$p-5 i$

\title{
MITT Writer and MITT Writer Advanced Development: Developing Authoring and Training Systems for Complex Technical Domains
}

\section{Final Report}

\author{
Bradley J. Wiederholt \\ Elica J. Browning \\ Jeffrey E. Norton \\ William B. Johnson \\ Galaxy Scientific Corporation
}

April 1991

Cooperative Agreement NCC 9-16

Research Activity No. ET.21 \& ET.22

NASA Johnson Space Center

Mission Operations Directorate

Space Station Training Office

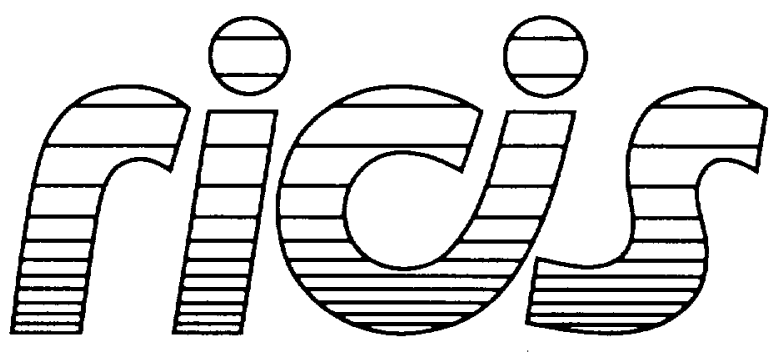

Research Institute for Computing and Information Systems

University of Houston-Clear Lake 


\section{The RICIS Concept}

The University of Houston-Clear Lake established the Research Institute for Computing and Information Systems (RICIS) in 1986 to encourage the NASA Johnson Space Center (JSC) and local industry to actively support research in the computing and information sciences. As part of this endeavor, UHCL proposed a partnership with JSC to jointly define and manage an integrated program of research in advanced data processing technology needed for JSC's main missions, Including admintstrative, engineering and science responsi bilities. JSC agreed and entered into a continuing cooperative agreement with UHCL beginning in May 1986, to fointly plan and execute such research through RICIS. Additionally, under Cooperative Agrcement NCC 9-16, computing and educational facilities are shared by the two institutions to conduct the research.

The UHCL/RICIS mission is to conduct, coordinate, and disseminate research and professional level education in computing and information systems to serve the needs of the government, industry, community and acadcmia. RICIS combines resources of UHCL and its gateway affiliates to research and develop materials, prototypes and publications on topics of mutual interest to its sponsors and researchers. Within UHCL, the mission is being implemented through interdisciplinary involvement of faculty and students from each of the four schools: Business and Public Administration, Education. Human Sciences and Humanities, and Natural and Applied Sciences. RICIS also collaborates with industry in a companion program. This program is focused on serving the research and advanced development needs of industry.

Moreover, UHCL established relationships with other universities and research organizations, having common research interests, to provide additional sources of expertise to conduct needed research. For example, UHCL has entered into a special partnership with Texas A\&M University to help oversee RICIS research and education programs, while other research organizations are involved via the "gateway" concept.

A major role of RICIS then is to find the best match of sponsors, researchers and research objectives to advance knowledge in the computing and information sciences. RICIS, working jointly with its sponsors, advises on research needs, recommends principals for conducting the research, provides tech nical and administrative support to coordinate the research and integrates technical results into the goals of UHCL, NASA/JSC and industry. 


\section{MITT Writer and MITT Writer Advanced Development: Developing Authoring and Training Systems for Complex Technical Domains}

Final Report 

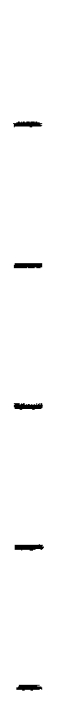

$-$

- 


\section{Preface}

This research was conducted under auspices of the Research Institute for Computing and Information Systems by Galaxy Scientific Corporation. Dr. Glenn B. Freedman served as RICIS research coordinator.

Funding has been provided by the Mission Operations Directorate, NASA/JSC through Cooperative Agreement NCC 9-16 between the NASA Johnson Space Center and the University of Houston-Clear Lake. The NASA technical monitor for this activity was Barbara N. Pearson, of the Systems/Elements Office, Space Station Training Office, Mission Operations Directorate, NASA/JSC.

The views and conclusions contained in this report are those of the authors and should not be interpreted as representative of the official policies, either express or implied, of NASA or the United States Government. 


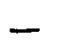

$-$

-

$-$

-

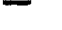

-

-

-

$-$

$-$

- 
MITT Writer and

MITT Writer Advanced Development:

Developing Authoring and Training Systems

for Complex Technical Domains

Final Technical Report

\author{
Bradley J. Wiederholt \\ Elica J. Browning \\ Jeffrey E. Norton \\ William B. Johnson \\ Galaxy Scientific Corporation \\ 2310 Parklake Drive \\ Suite 300 \\ Atlanta, Georgia 30345-2904
}

\begin{abstract}
Prepared for:
Armstrong Laboratory Human Resources Directorate Training Systems Division

Brooks Air Force Base, Texas 78235-5601
\end{abstract}

RICIS Research Activity Number E.T. 21

Subcontract Number 58 and

RICIS Research Activity Number E.T. 22

Subcontract Number 59

April 1991 


\section{Executive Summary}

MITT Writer is a software system for developing computer-based training for complex technical domains. A training system produced by MITT Writer allows a student to learn and practice troubleshooting and diagnostic skills.

The MITT (Microcomputer Intelligence for Technical Training) architecture is a reasonable approach to simulation-based diagnostic training. MITT delivers training on available computing equipment, delivers challenging training and simulation scenarios, and has economical development and maintenance costs.

A 15-month effort was undertaken in which the MITT Writer system was developed. A workshop was also conducted to train instructors how to use MITT Writer. Earlier versions were used to develop an Intelligent Tutoring System for troubleshooting the Minuteman Missile Message Processing System. 


\section{Acknowledgments}

The work described was supported by the Training Systems Division of Armstrong Laboratory Human Resources Directorate, under RICIS Research Activity Number E.T. 21, Subcontract Number 58 and RICIS Research Activity Number E.T. 22, Subcontract Number 59. Mr. Jim Fleming served as scientific monitor for the projects. Major Jim Parlette, Capt. Kevin Glass, Capt. Mike Slaven, and Mr. Wes Regian of the Human Resources Directorate monitored and supported the development of the MITT and MITT Writer systems.

Mr. Ernesto Podagrosi, MSgt. Wayne Griffin, and MSgt. Rick Olsen of Chanute AFB were insturmental in the development and review of the Minuteman Missile Message Processing tutor.

Our colleagues Leonard Utsman, William Pitts, and Leslie Neste assisted in the design, development, and evaluation of the MITT and MITT Writer systems. 


\section{Table of Contents}

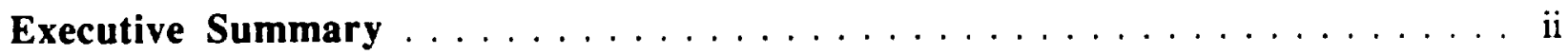

Acknowledgments $\ldots \ldots \ldots \ldots \ldots \ldots \ldots \ldots \ldots \ldots$

Table of Contents $\ldots \ldots \ldots \ldots \ldots \ldots \ldots \ldots \ldots$

Figures and Tables $\ldots \ldots \ldots \ldots \ldots \ldots \ldots \ldots \ldots \ldots$ vi

1.0 Introduction $\ldots \ldots \ldots \ldots \ldots \ldots \ldots \ldots \ldots \ldots \ldots \ldots \ldots \ldots$

1.1 Overview $\ldots \ldots \ldots \ldots \ldots \ldots \ldots \ldots \ldots \ldots \ldots$

1.2 Report Organization $\ldots \ldots \ldots \ldots \ldots \ldots \ldots \ldots \ldots \ldots \ldots \ldots \ldots$

2.0 Foundations of MITT Writer $\ldots \ldots \ldots \ldots \ldots \ldots \ldots \ldots$

2.1 Early Research $\ldots \ldots \ldots \ldots \ldots \ldots \ldots \ldots \ldots \ldots \ldots \ldots$

2.2 The Next Step - MITT (Microcomputer Intelligence for

Technical Training) ..................... 5

3.0 Goals for MITT and MITT Writer $\ldots \ldots \ldots \ldots \ldots \ldots$

3.1 Candidate Domains for MITT Tutors $\ldots \ldots \ldots \ldots \ldots \ldots$

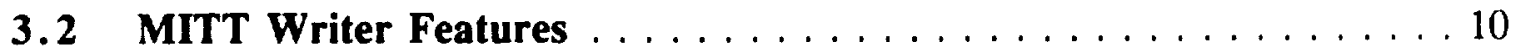

3.3 System Requirements $\ldots \ldots \ldots \ldots \ldots \ldots \ldots \ldots$

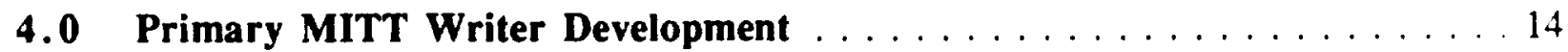

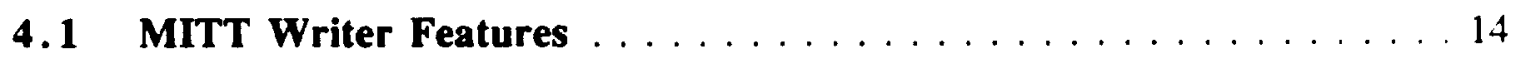

4.1 .1 MrTT Writer Objects . . . . . . . . . . . . . . . 14

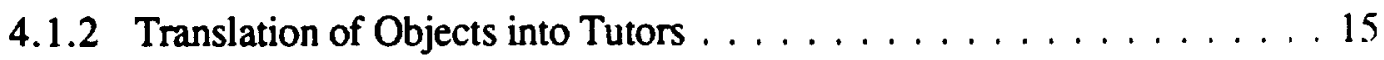

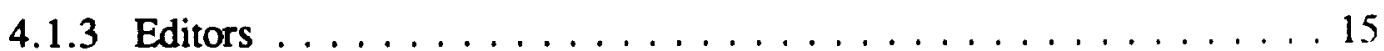

4.1.4 User-Interface . . . . . . . . . . . . . . . . . . . . 16

4.1.5 Interactive Display Editor $\ldots \ldots \ldots \ldots \ldots \ldots \ldots \ldots$

4.1 .6 MrTT Writer Advisor . . . . . . . . . . . . . . . . . . . . 19 


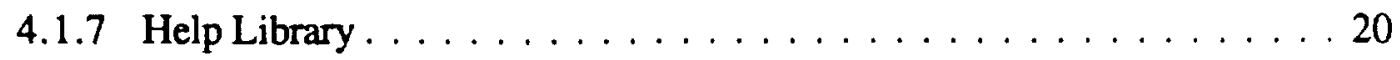

4.1.8 Error and Consistency Checking $\ldots \ldots \ldots \ldots \ldots \ldots$

4.1 .9 Database Support . . . . . . . . . . . . . . . . . . 22

4.2 The MITT Writer Authoring Process $\ldots \ldots \ldots \ldots \ldots \ldots 22$

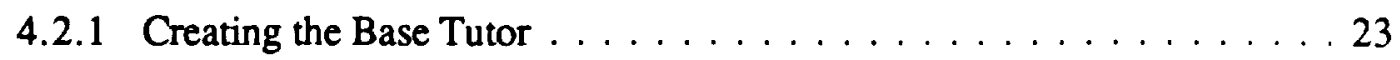

4.2.2 Demonstration and Modification . . . . . . . . . . . . . . 27

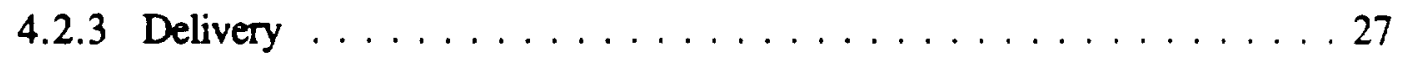

4.3 MITT Writer Internal Architecture $\ldots \ldots \ldots \ldots \ldots \ldots$

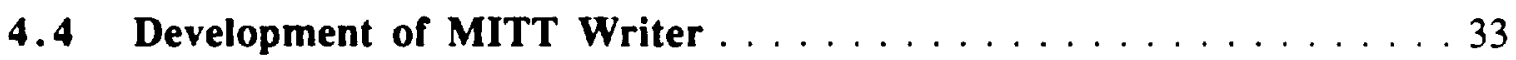

5.0 MITT Writer Advanced Development $\ldots \ldots \ldots \ldots \ldots \ldots \ldots \ldots$

5.1 Minuteman Missile Message Processing Tutor $\ldots \ldots \ldots \ldots 35$

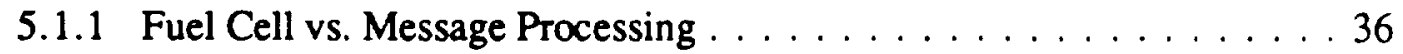

5.1 .2 MITT Writer and MITT . . . . . . . . . . . . . . . . . . . 39

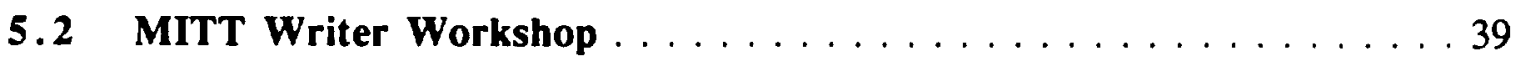

5.2 .1 Workshop Format $\ldots \ldots \ldots \ldots \ldots \ldots \ldots \ldots$

5.2 .2 Evaluation Results . . . . . . . . . . . . . . . 40

6.0 Summary and Areas for Future Development $\ldots \ldots \ldots \ldots \ldots \ldots$

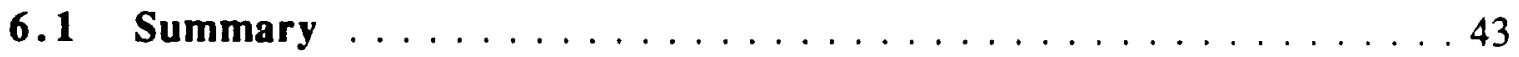

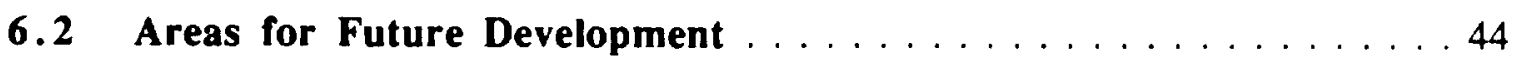

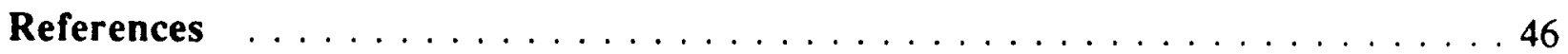




\section{Figures and Tables}

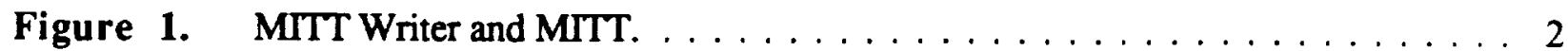

Figure 2. Sample Portion of Functional Flow Diagram for a Car Engine. . . . . . . . . 5

Figure 3. Example Display from the MITT Fuel Cell Tutor Prototype. . . . . . . . . . . 6

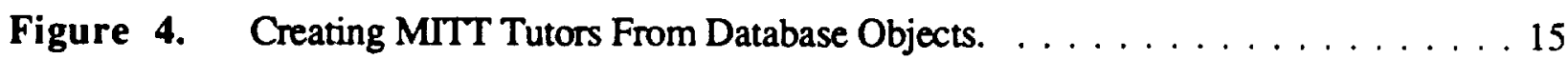

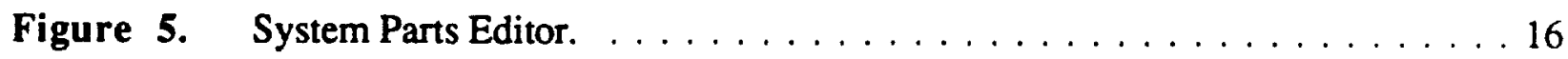

Figure 6. Database Menu. . . . . . . . . . . . . . . . . . . . . . 17

Figure 7. A Stack of Object Editor Windows. . . . . . . . . . . . . . . . . 17

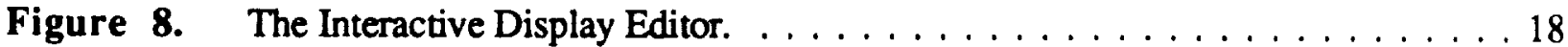

Figure 9. Data Field Editor. . . . . . . . . . . . . . . . . . . . . . . . 19

Figure 10. Sample Suggestion From MITT Writer Advisor. . . . . . . . . . . . . . 20

Figure 11. Sample Display from the MITT Writer Help Library. . . . . . . . . . . . . . . 21

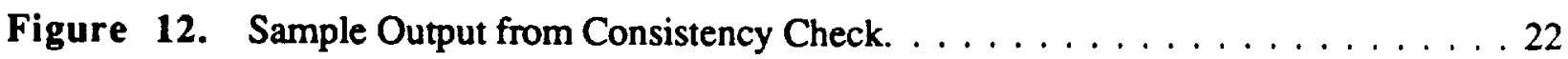

Figure 13. Overview of the MITT Writer Authoring Process. . . . . . . . . . . . . . 23

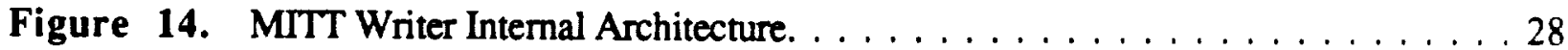

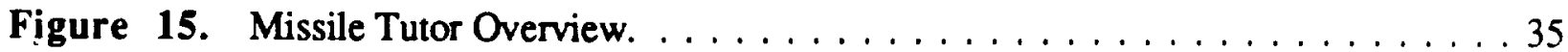

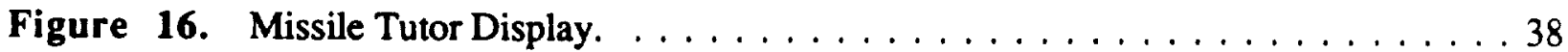

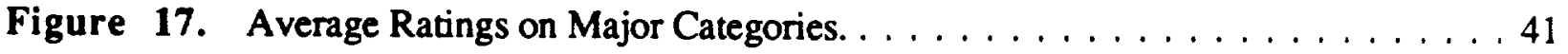

Figure 18. MITT Training System Scores - Overall. . . . . . . . . . . . . . . 41

Figure 19. MITT Writer Ratings - Overall. . . . . . . . . . . . . . . . . . 42

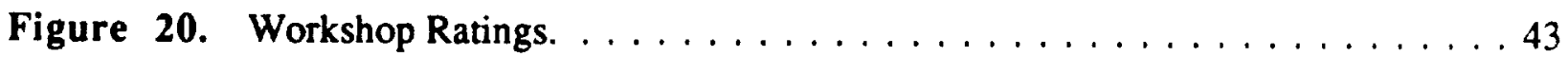

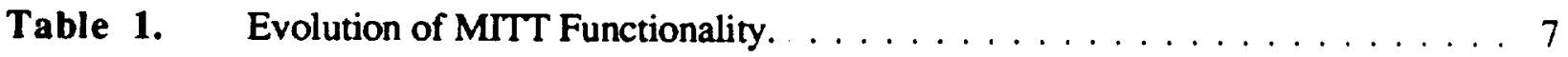

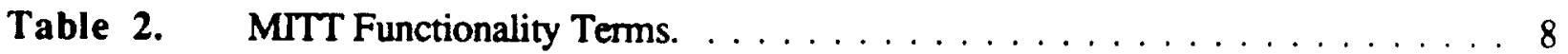

Table 3. Characteristics of Candidate Domains for MITT Tutors. . . . . . . . . . . 11

Table 4. MITT Writer Features. . . . . . . . . . . . . . . . . . 12 


\subsection{Introduction}

\subsection{Overview}

MITT Writer is a software system for developing computer-based training for complex technical domains. A training system produced by MITT Writer allows a student to learn and practice troubleshooting and diagnostic skills. In the training system, a problem is presented to a student in which a domain component has failed. The student is then presented with a simulation of the system. The student is given initial information about the problem, and then proceeds to gather additional information by viewing gauges and displays, testing components, obtaining expert procedural and functional advice and, eventually, locating the failed component.

The training system produced by MITT Writer focuses on simulation-oriented training. The training scenario relies on the simulation of gauges and instrumentation to provide the student with troubleshooting practice. During a problem session, the student receives advice that is both functional (common sense advice based on system connectivity) and procedural (based on technical orders). The student practices these troubleshooting and diagnosis techniques during several problem sessions.

Like all previous MITT (Microcomputer Intelligence for Technical Training) projects (Johnson et al., 1985; Johnson et al., 1988; Johnson et al., 1989), MITT Writer was designed to run on conventional, readily available microcomputers. Using MITT Writer, instructors and domain experts with minimal computer experience can design an Intelligent Tutoring System (TTS)1. The ITS is made up of a system simulation, a functional knowledge base, a procedural knowledge base, a simulation interface, and instructional guidance. These components are used by MITT (a companion software program) to provide students with the new technical training (see Figure 1).

This report describes the 15-month effort in which the MITT Writer and MITT software programs were developed. During this period, a workshop was also conducted to train instructors to use MITT Writer. This report also describes earlier versions of MITT that were used to develop an ITS for troubleshooting the Minuteman Missile Message Processing System. These activities were

1 General information on Intelligent Tutoring Systems can be found in (Johnson, 1988b; Massey et al, 1988; Polson \& Richardson, 1988). Detailed information on the particular ITS architecture employed by MITT is given in (Johnson, et al, 1988). 
conducted under two separate, but highly interrelated, projects: MITT Writer and MITT Writer Advanced Development.

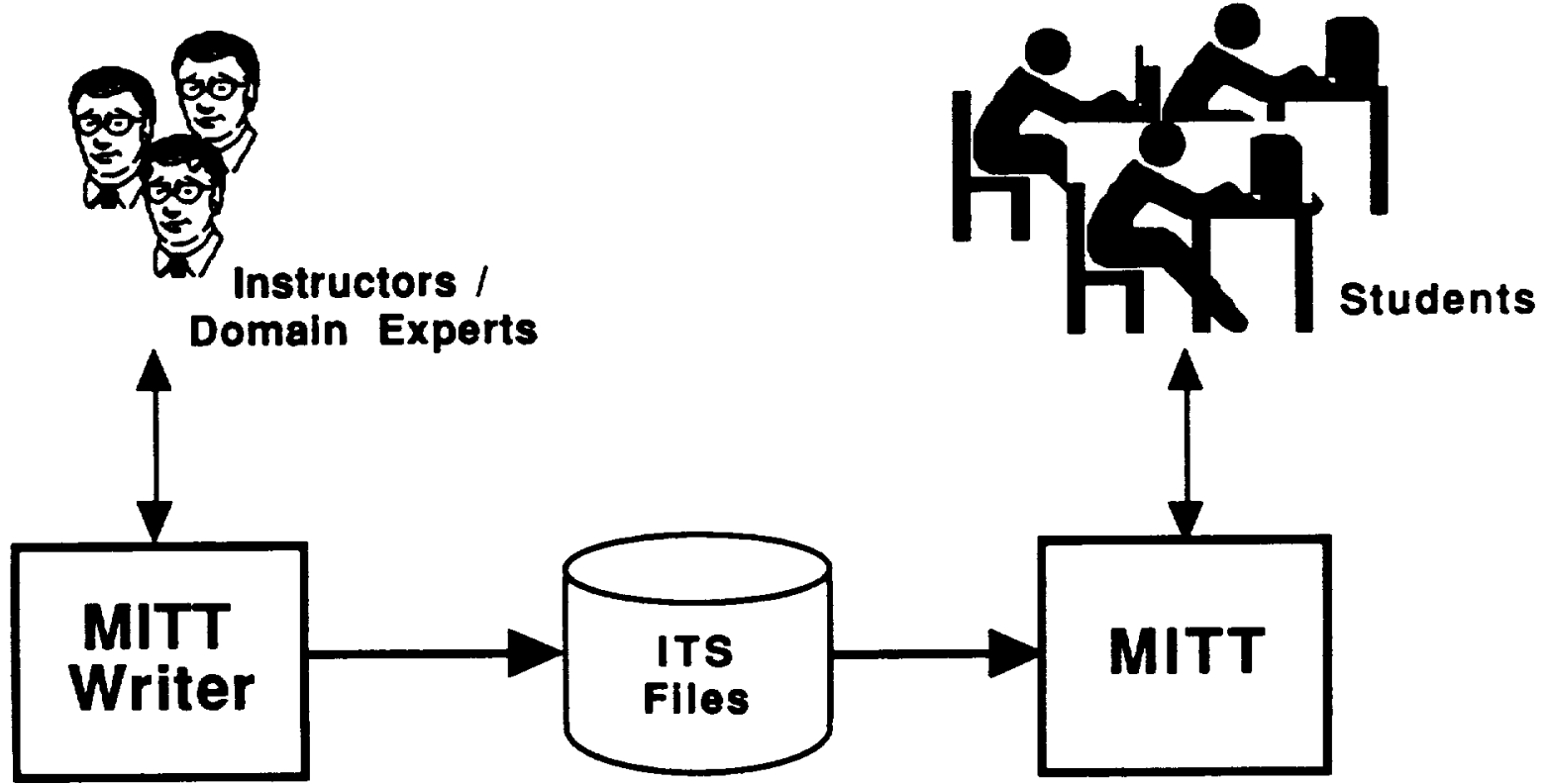

Figure 1. MITT Writer and MITT.

In the first project, MITT Writer, the MITT Writer authoring system was developed and demonstrated. With the authoring system, an Air Force instructor or domain expert develops Intelligent Tutoring Systems for training students to troubleshoot problems in complex technical domains. MITT Writer contains many features to support the instructor, including a graphical interface, a large help library, expert advice, and extensive error checking.

In the affiliate project, MITT Writer Advanced Development, the evolving training tools were used to develop a turn-key ITS for the Air Force. In addition, a workshop was conducted to teach prospective Air Force instructors to use MITT Writer. Their initial reaction to its operation was also assessed (Browning, et al., 1991).

Both of these projects proceeded in parallel. Early versions of the generic MITT delivery system were used to support the development and delivery of the turn-key ITS. Likewise, the subsequent design and interface modifications to the MITT Writer authoring system were based on the 
reactions and opinions of the workshop participants. Internal use of MrTT Writer in developing the Missile Message Processing Tutor also affected system modifications.

\subsection{Report Organization}

The remainder of this report describes the activities and results of the MITT Writer and MITT Writer Advanced Development projects. Section 2 describes previous work conducted by the authors that contributed to the current projects. Section 3 briefly presents the technical goals for the projects, and the technical approach to meeting these goals. Sections 4 and 5 describe the key issues of the MITT Writer and MITT Writer Advanced Development projects. Section 6 summarizes the project results and offers suggestions for future research. This report does not provide detailed operation directions for either MITT Writer or MITT. A companion report, the MITT Writer User's Reference Manual (Wiederholt, 1991), provides this information. 


\subsection{Foundations of MITT Writer}

\subsection{Early Research}

Previous efforts on part of the research team (Johnson, 1981; Johnson \& Rouse, 1981; Johnson, 1987) consisted of conducting basic troubleshooting skills research and applying this new knowledge to the development of Intelligent Tutoring Systems for a wide variety of technical domains. Early research (1979-1982) focused on understanding generic troubleshooting. The first of these studies was Troubleshooting by Application of Structural Knowledge (TASK). TASK (Rouse, 1979) provided a variety of context-free simulations that enhanced the understanding of basic problem-solving. The context-free training research permitted laboratory experimentation of such variables as problem complexity, type of feedback, computer aiding, and forced pacing. The research indicated that problem-solving simulations had significant potential for "real-world" diagnostic training. This early research prompted context-specific training simulations.

Framework for Aiding and Understanding of Logical Troubleshooting (FAULT) added domain context to the problem solving sessions, and allowed a student to troubleshoot a network of parts by checking instruments and making observations (Johnson 1981; Rouse \& Hunt, 1984). The FAULT simulation also introduced the concept of the functional flow diagram (FFD).

The FFD taught the student to understand the concept of functional connectivity. The concept views a system as interconnected parts with "function" flowing through the system. For a part to provide proper function, all parts that connect to it and the part itself must be fully operational. This concept promotes a generic approach to all system diagnosis. A sample portion of a FFD for a car engine is given in Figure 2.

The basic laboratory research described above was transferred to the field with the Army SB-3614 tactical switchboard training system (Johnson and Fath, 1983 \& 1984). SB-3614 examined the feasibility of using off-the-shelf microcomputers for training in the Army school environment. This effort found that low-fidelity training simulation (dictated by hardware limitations) was acceptable, but could be enhanced by practice on the real equipment (Johnson and Fath, 1984). The SB-3614 software was adopted into the Army program of instruction and was used from 1984 until 1988, when the SB-3614 equipment was retired from the Army inventory. 


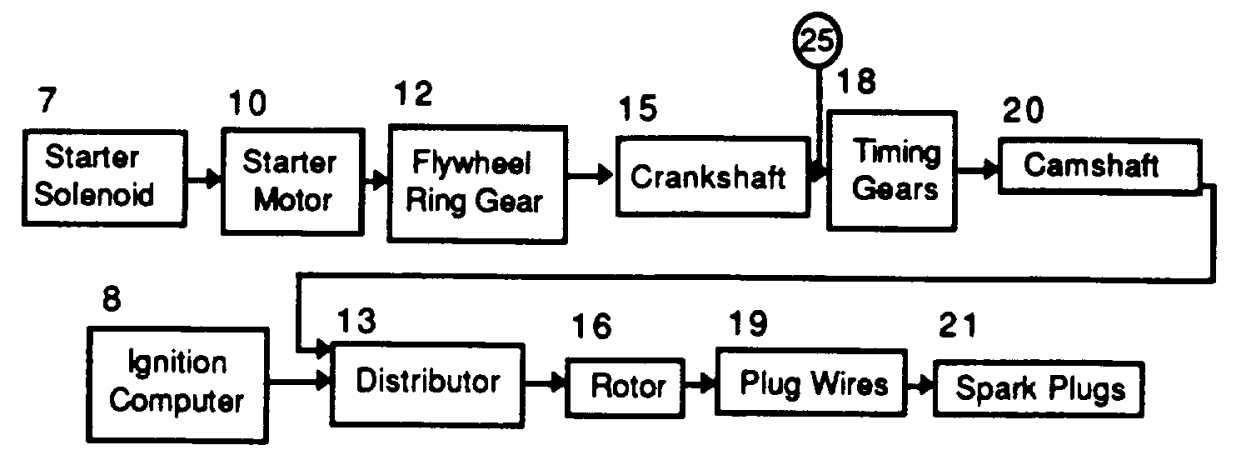

Figure 2. Sample Portion of Functional Flow Diagram for a Car Engine.

The concepts of functional flow and simulation-oriented training from FAULT were later applied to the Diesel Generator Simulator (DGSIM) (Johnson et al., 1985; Johnson et al., 1986). DGSIM provided improved graphics and simulation scenarios, thus enabling the student to 'visit' various information sources, rather than relying on the single model of functional flow. DGSIM also added the ability to generate advice to the student based upon the functional flow of the system.

The DGSIM research was significant because of the extensive post-training evaluation that was conducted. The evaluation compared the use of computer simulation to traditional training. The results showed that the simulation-based training is significantly better, particularly with respect to long-term retention (Maddox et al., 1986).

\subsection{The Next Step - MITT (Microcomputer Intelligence for Technical Training)}

Work on initial versions of Microcomputer Intelligence for Technical Training (MITT) began in 1987 (Johnson et al., 1988). The first MITT prototype was a proof-of-concept software program designed to show than an effective ITS could be developed inexpensively on common and readily available microcomputers. The system was based on the functionality provided by DGSIM, and provided additional enhancements to both the simulation and tutoring capabilities. The domain for the prototype was the Electrical Power System/Fuel Cell for the Space Shuttle. Additional features provided by this prototype included static data representation, procedural advice, EGA 640×200 graphics, and unsolicited instructor feedback. Figure 3 shows an example display from the prototype. 


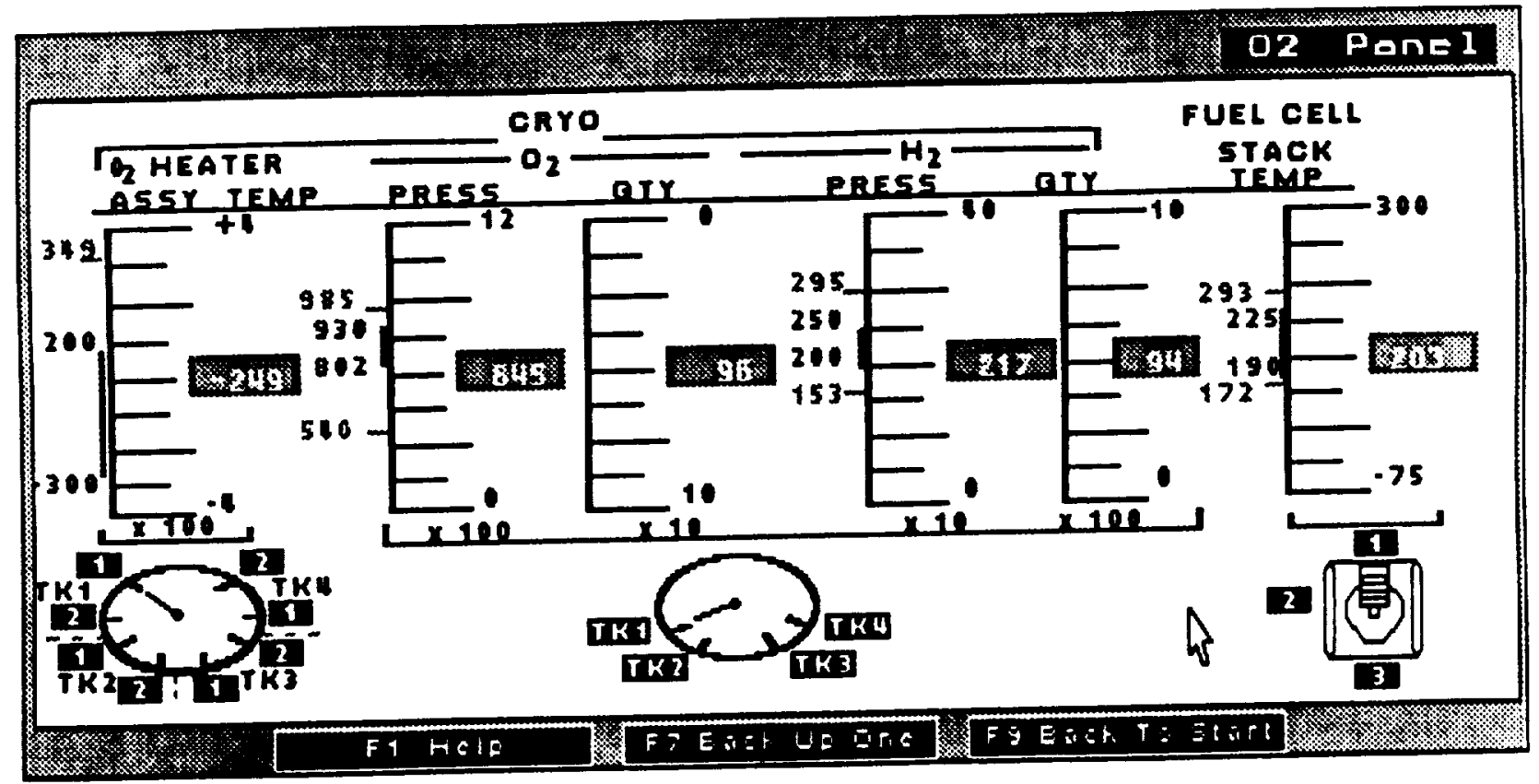

Figure 3. Example Display from the MIT Fuel Cell Tutor Prototype.

A subsequent MIT project enhanced the prototype to become the MITT Fuel Cell Tutor. The Fuel Cell Tutor included additional problem scenarios, dynamic data representation, an animated system schematic and overall performance enhancements (Johnson et al., 1989; Neste 1989). The Fuel Cell Tutor was evaluated at NASA Johnson Space Center for training of astronauts and flight controllers (Johnson, et al., 1988).

As an overview, Table 1 (from Norton, et al., 1990) offers a brief look at the progression of functionality provided by MITT over the past 4 years. Table 2 provides a glossary for the terminology used in Table 1.

Also during the last development round of the MITT Fuel Cell Tutor, a specification for an authoring system was generated (Johnson et al., 1989). An authoring system would allow instructors or domain experts with minimal computer experience to develop their own ITSs. These new training systems would be based on the MITT architecture and, like MITT, would be able to run on standard Air Force microcomputers. Subsequent sections describe the technical hurdles that were overcome to develop such an authoring system. 
Table 1. Evolution of MITT Functionality.

\begin{tabular}{|c|c|c|c|c|c|}
\hline & DGSIM & MITT Proto & Fuel Cell & $\begin{array}{l}\text { MIssile } \\
\text { Tutor }\end{array}$ & MITT Core \\
\hline $\begin{array}{l}\text { Functlonal } \\
\text { Advice }\end{array}$ & $\begin{array}{l}\text { Includes time, } \\
\text { most powerful, } \\
\& \text { best test }\end{array}$ & $\begin{array}{l}\text { Includes only } \\
\text { best test }\end{array}$ & Same & Same & Same \\
\hline \multirow[t]{2}{*}{ SImulation } & $\begin{array}{l}\text { System is a } \\
\text { snapshot. Data } \\
\text { values constant }\end{array}$ & Same & $\begin{array}{l}\text { Adds simulation } \\
\text { dynamics }\end{array}$ & Same & Same \\
\hline & & $\begin{array}{l}\text { Adds links } \\
\text { between } \\
\text { mouseable } \\
\text { regions \& tests }\end{array}$ & Same & Same & Same \\
\hline $\begin{array}{l}\text { Anlmated } \\
\text { Flow }\end{array}$ & None & None & Adds animation & Same & Same \\
\hline $\begin{array}{l}\text { Procedural } \\
\text { Advice }\end{array}$ & None & Used CLIPS & Same & $\begin{array}{l}\text { Expands student } \\
\text { model }\end{array}$ & Same \\
\hline Graphics & CGA 4-color & $\begin{array}{l}\text { EGA } 640 \times 200 \text {. } \\
\text { Uses custom } \\
\text { decompression } \\
\text { routines }\end{array}$ & $\begin{array}{l}\text { Refines } \\
\text { decompression } \\
\text { routines }\end{array}$ & $\begin{array}{l}\text { Uses 3rd party } \\
\text { PCX package } \\
\text { EGA } 640 \times 350\end{array}$ & Same \\
\hline Time & $\begin{array}{l}\text { Tracks time } \\
\text { required to } \\
\text { perform tests }\end{array}$ & $\begin{array}{l}\text { No longer tracks } \\
\text { time }\end{array}$ & Same & Same & Same \\
\hline $\begin{array}{l}\text { Instructor } \\
\text { Feedback }\end{array}$ & $\begin{array}{l}\text { Limited to FFD } \\
\text { advice }\end{array}$ & $\begin{array}{l}\text { Add unsolicited } \\
\text { feedback } \\
\text { (beyond FFD } \\
\text { advice) }\end{array}$ & Same & Same & Same \\
\hline Subsystems & Multiple & Same & Single & Same & Same \\
\hline Memory & One executable & $\begin{array}{l}\text { Four separate } \\
\text { executables } \\
\text { (Main, Info, } \\
\text { Sim. CLIPS) }\end{array}$ & Same & $\begin{array}{l}\text { Two executables } \\
\text { Info/Sim and } \\
\text { Clips }\end{array}$ & $\begin{array}{l}\text { Overlays yield } \\
\text { one executable }\end{array}$ \\
\hline Flle-Based & No & No & No & Yes & Yes \\
\hline
\end{tabular}


Table 2. MITT Functionality Terms.

Term

Functional Advice

Simulation

Animated

Flow

Procedural Advice

Graphics

Time

Instructor

Feedback

Subsystems

Memory

File-Based

\section{Definition}

The advice that is given to the student is based on the functional flow diagram (FFD). Functional advice knows only that part A is connected to part B, etc. No domain-specific advice can be given here.

The term simulation is used here to refer to how the data values used by the system are updated. These data values can be generated in a variety of ways, ranging from the use of static data representations to the use of full-fidelity simulation.

The function of the system flows from one part to the next. The flow from one part to another part can be represented with some simple animation on the screen.

Many technical training domains enlist specific troubleshooting procedures. The procedural advisor captures this procedural knowledge in the form of rules.

The interface to MITT uses a large number of graphics. As the system has evolved, the resolution of the pictures and the manner in which these graphics are presented has changed.

The amount of simulated time required to perform a test or to replace a part.

The unsolicited feedback is similar to the feedback that would be given by a human instructor looking over the student's shoulder.

The size of the domain depends on two parameters: 1) the size of the executable system, and 2) the size of the domain-specific files. Sometimes the domain needs to be subdivided into several smaller systems to fit into available memory. Each of these systems are referred to as "subsystems."

The need for memory conservation is essential because of the 640 Kilobyte memory restriction in DOS. Several tactics were used to conserve memory during the evolution of MITT.

In preparation for MITT Writer, all domain-specific information was removed from the code and placed into data files. In Table 1, "yes" indicates that this operation was performed, "no" indicates that the code still contained domainspecific references. 


\subsection{Goals for MITT and MITT Writer}

The initial acceptance of the Fuel Cell and Missile tutors suggested that the MITT tutor architecture is a reasonable alternative for simulation-based diagnostic training. For the MITT tutoring philosophy to be widely accepted into DoD and other government and/or industry training programs, there are three primary criteria that must be met:

- The training technology must deliver training on available computing equipment,

- The training technology must deliver challenging training and simulation scenarios,

- The training technology must have reasonable development and maintenance costs.

If MITT tutors are going to have wide-spread acceptance, they must operate on computer systems that are already installed in training installations. In the DoD environment, as well as many other training environments, the common computer is a 80286-based DOS machine with, at most, 640 Kilobytes of RAM. EGA color displays, combined with keyboard and mouse input, are also quite common. The MITT series of training tools was designed to operate within these constraints.

MITT tutors must be able to provide challenging, simulation-based problems to students. The architecture used for the MITT tutors is simulation-based, permitting the student to engage in most of the diagnostic actions that are available with real equipment. This design must be available for any new MITT tutor.

The development and maintenance of a MITT tutor must be affordable. This goal can be achieved with the creation of a development environment that can be used by government training developers and subject matter experts. Technical instructors are likely users of such development tools (Johnson, 1988a). The MITT Writer authoring environment must guide technical personnel to organize their knowledge in a format that is aligned with the MITT architecture. The system must be relatively easy to use. It must guide the developer, provide help and advice with the development, and check the newly created system for completeness.

As introduced in Section 1.0, the MITT training environment (initially proposed in Johnson, et al., 1989) consists of two separate software programs: MITT Writer and MITT. MITT Writer is a development environment used by instructors and subject matter experts to produce a description of training. In contrast, MITT delivers the instruction that was developed using MITT Writer. 
The goal of MITT Writer is to support instructors and subject matter experts, rather than programmers, in developing MITT tutors. MITT Writer should provide enhanced ITS authoring capabilities. MITT Writer should allow the author to rapidly develop and maintain MITT tutors. In contrast, the goal of MITT is to deliver training to students using ITS technology. MITT should use data produced by MITT Writer to present problems, monitor student performance, compare student actions to expert actions, and present suitable feedback to the student. MITT should work with any set of description files produced by MITT Writer.

The following sections outline the technical design environment (both goals and constraints) for the implementation of MITT Writer and the MITT training delivery software.

\subsection{Candidate Domains for MITT Tutors}

MITT Writer was designed to build MITT tutors for technical domains that exhibit the characteristics shown in Table 3.

\subsection{MITT Writer Features}

MITT Writer was designed with a variety of features to aid an instructor or domain expert in developing a new MITT Tutor. Most of these features were derived by analyzing the information needs of the MITT Writer user and the data requirements of the MITT software. Table 4 presents a list of these features. Each of these features will be discussed in more detail in Section 4.0. 
Table 3. Characteristics of Candidate Domains for MITT Tutors.

- Complex Technical System - MITT can address a variety of interconnected components within a large system.

- System has a Variety of Instrumentation - MITT uses instruments as a basis for all testing. The more instruments that are available, the better the simulation can represent the real system.

- System Has Multiple Test Points - The MITT functional model splits the system by obtaining information at many points in the technical system. Multiple, real-world test points enhance the functional model.

- Students Must Practice to be Proficient - MITT permits continuing practice. MITT problem sessions typically tend to be low in time (e.g., around 15 minutes per problem), enhancing the accessibility by the students.

- Students Need Procedural Information - The MITT procedural advisor is constructed from system diagnostic procedures. If such procedures exist, and are robust, then the MITT procedural expert will be correspondingly powerful.

- Students Cannot Practice on Real Equipment - If the real equipment is simply not available for safe, effective, and efficient practice, then it is worthwhile to invest in the development of a MITT Tutor.

- Student's Job Has Diagnostic Tasks - If the job has a large troubleshooting component, the trainee must practice to learn and to sustain diagnostic knowledge and skill. If the job does not involve troubleshooting, MITT may not be the best training approach. If the job has low amounts of troubleshooting, but such troubleshooting is critical, then MITT is also appropriate. 


\section{Table 4. MITT Writer Features.}

- $\quad$ MITT Writer provides an editor for each particular training item, such as system parts, system sensors, simulation displays, diagnostic procedures, and instructor guidance.

- MITT Writer capitalizes on graphical user-interface technology using a windowed, menu-based, mouse-driven interface.

- MITT Writer provides tools for graphical screen composition and layout.

- MITT Writer contains on-line intelligent advice on how to use MITT Writer.

- $\quad$ MITT Writer contains an extensive help library, including context-specific help.

- MITT Writer provides on-line error checking for data correctness, completeness, and consistency.

- $\quad$ MITT Writer saves work-in-progress and completed work in databases, allowing authors to continue their work over several sessions.

MITT Writer creates new MITT tutors by translating an authored database into training description files. 


\subsection{System Requirements}

One important goal of all previous MITT projects was to produce software that operates on standard, and commonly available, computing environments. MITT Writer was also designed with this goal in mind. MITT Writer also capitalizes on existing graphics tools to support its ITS authoring functions.

MITT Writer requires an IBM PC/AT or higher DOS-based platform to operate. Noticeable performance increases can be observed when running MITT Writer on 80386-class machines. RAM requirements are set at $640 \mathrm{~K}$ or higher, though 1 Megabyte of RAM is recommended. 640K of the total system memory must be conventional memory, and the remainder of the memory must conform to either the Extended Memory Manager (XMS) or Expanded Memory Manager (EMS) specifications. Noticeable improvements can be observed when the memory conforms to the EMS specifications. On AT-class machines, this often requires the addition of EMS-specific memory expansion boards, though some software packages exists that can map conventional XMS memory to EMS specifications. On 386-class machines, software (such as QEMM by Quarterdeck) is widely available to support the EMS standard.

A Microsoft Mouse (or compatible) is highly recommended, but not required for using the basic MITT Writer editors. However, a mouse is required for the Interactive Display Editor. MITT Writer operates in standard 16-color EGA video mode. At least 3 Megabytes of hard disk space should be dedicated to MITT Writer to ensure optimal performance.

MITT Writer was not designed to support bit-mapped editing of graphics. This function is left to the numerous commercial and public domain packages that are available for producing .PCX format image files. Any pictures that are produced for use in MITT Writer must be in standard EGA format (i.e., 16-color, $640 \times 350$ resolution). 


\subsection{Primary MITT Writer Development}

As mentioned earlier, MITT Writer was designed with a variety of features to aid an instructor or domain expert in developing a new MITT Tutor. This section discusses these features, focuses on the MITT Writer authoring process, examines the internal architecture of MITT Writer, and discusses project development issues.

\subsection{MITT Writer Features}

\subsubsection{MTT Writer Objects}

MITT Writer allows authors to develop training systems for complex technical domains. Authors use MITT Writer to create, modify, and store objects related to the technical domain. In MITT Writer, major object classes are:

- System Components, including Parts and Sensors

- System Alarms and Faults

- Problems

- Interface Displays, including Information and Simulation Displays

- $\quad$ System Procedures

- Instructor Guidance

Taken as a whole, these object classes represent the Simulation, Procedural, Student Modeling, Instructional, and Interface components of a MITT tutor.

Within each of these major object types are sub-objects. For example, a Simulation Display object would have sub-objects describing controls, display elements, and active screen regions. A System Procedure would have sub-objects pertaining to the steps of the procedures and advice given during that step.

In addition to allowing the author to manipulate and store objects, MITT Writer also allows the author to modify relationships between these objects. For example, system parts are related to one another based on their functional flow, and alarms and faults are related to particular problems. 


\subsubsection{Translation of Objects into Tutors}

As shown in Figure 4, MIT Writer creates new MITT tutors by translating from MITT Writer objects into ITS (Intelligent Tutoring System) files. These ITS files are used by MITT to present the desired training to the student.

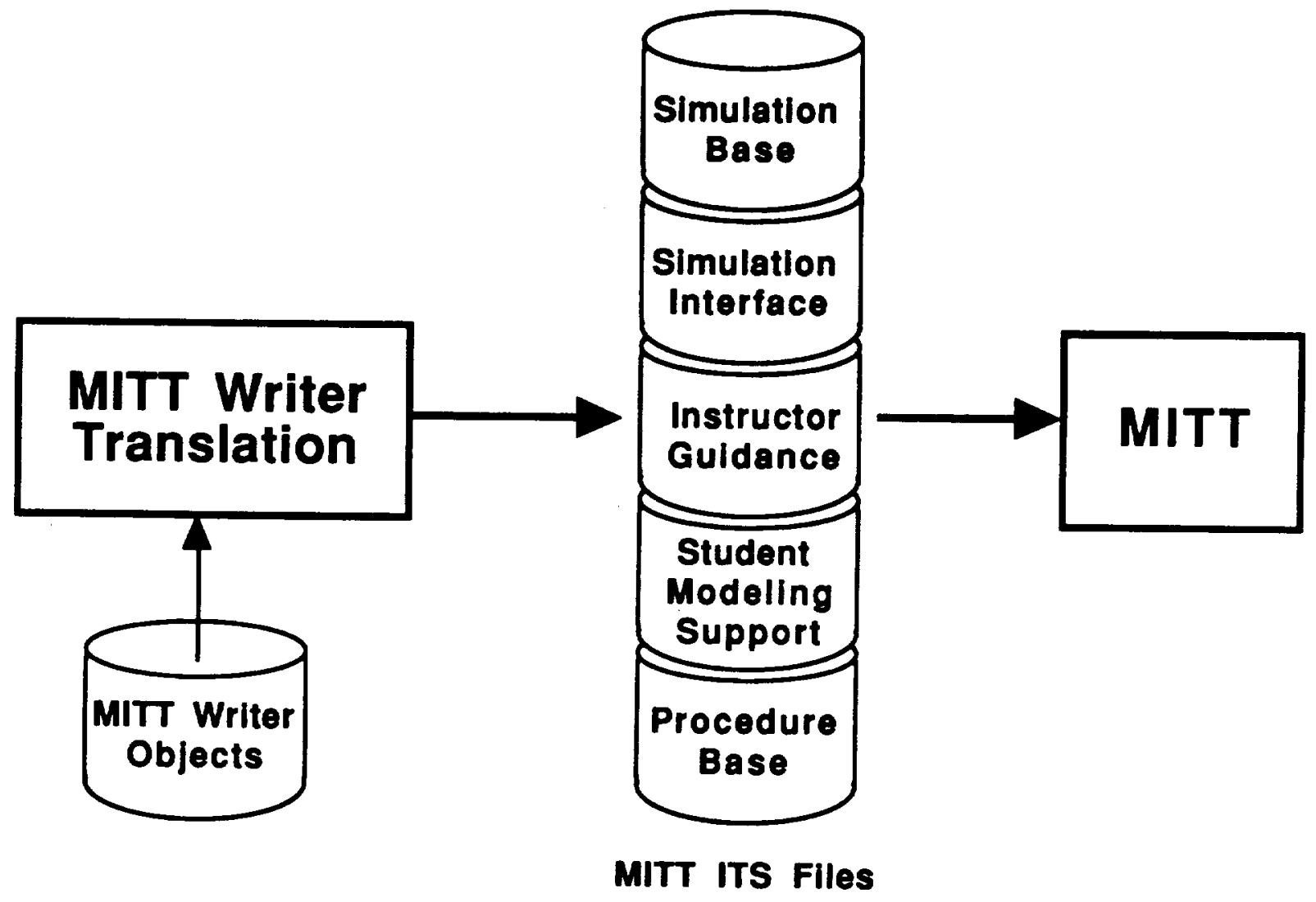

Figure 4. Creating MITT Tutors From Database Objects.

\subsubsection{Editors}

MITT Writer provides an editor for each particular training object. For example, the System Parts editor (see Figure 5) allows the author to modify the part's number, name, general description and test descriptions, functional feedback, and relationship to other parts in the system. An editor allows the author to edit both the object and its relationships. 


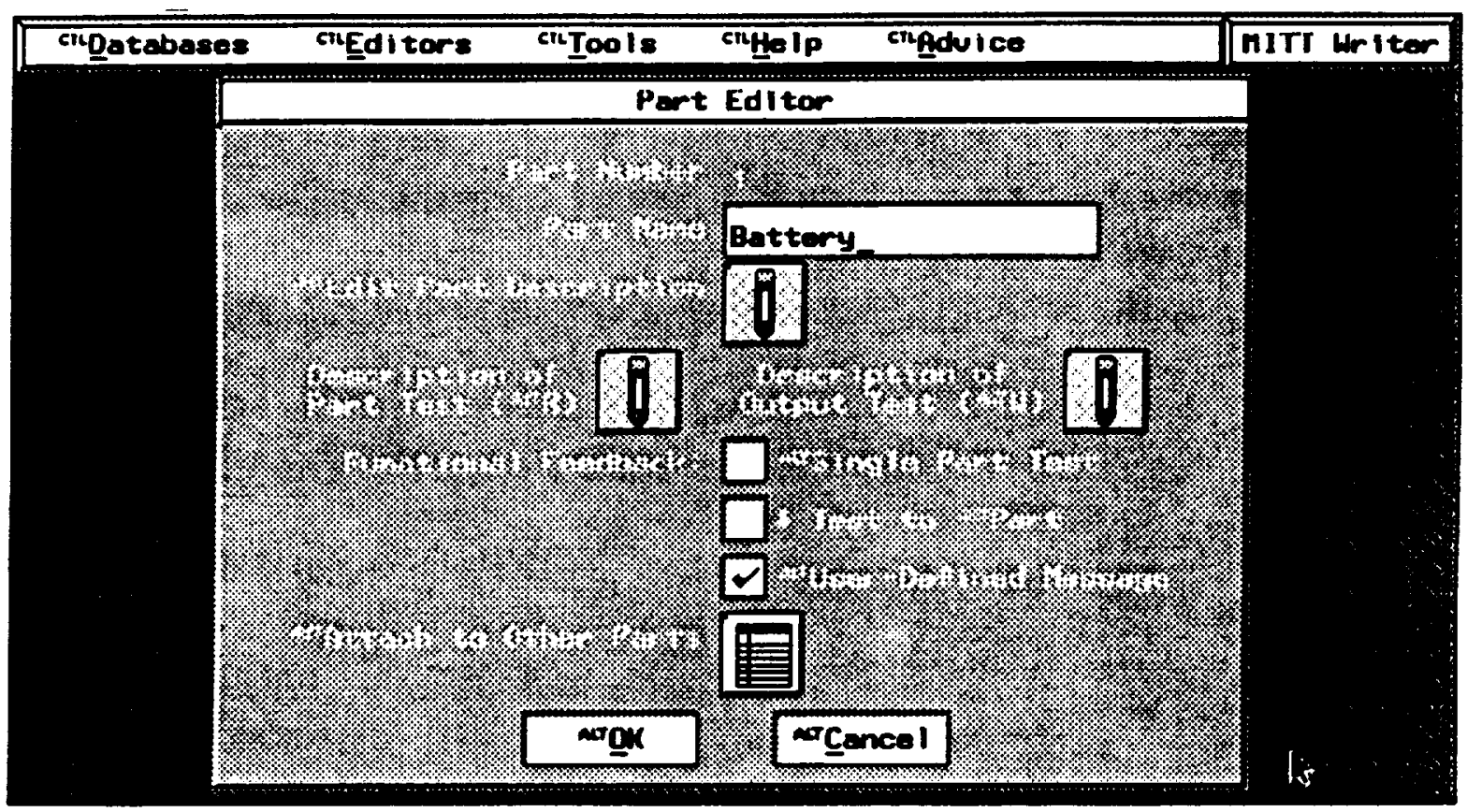

Figure 5. System Parts Editor.

\subsubsection{User-Interface}

MITT Writer capitalizes on graphical user-interface technology by using a windowed, menu-based, mouse-driven interface. This direct-manipulation style interface supports the data entry, editing, and object management tasks performed by the author. Menus provide the author with the ability to quickly select commands and tools. Figure 6 shows an example menu for all operations related to using databases. Windows, on the other hand, logically group the author's work on the display. All work related to a particular object is located in a window for that object. Figure 7 shows a stack of windows for a variety of editors. 


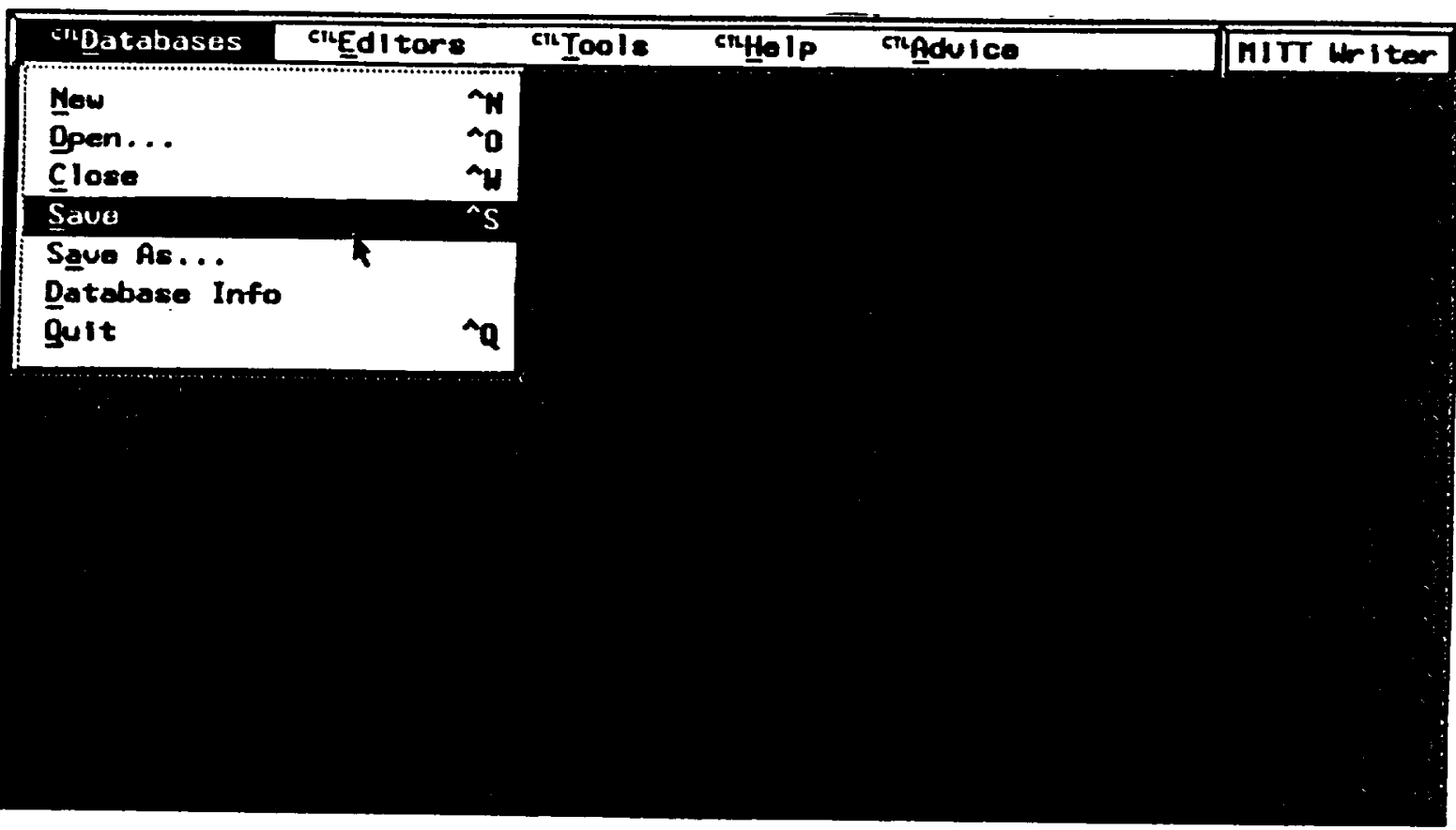

Figure 6. Database Menu.

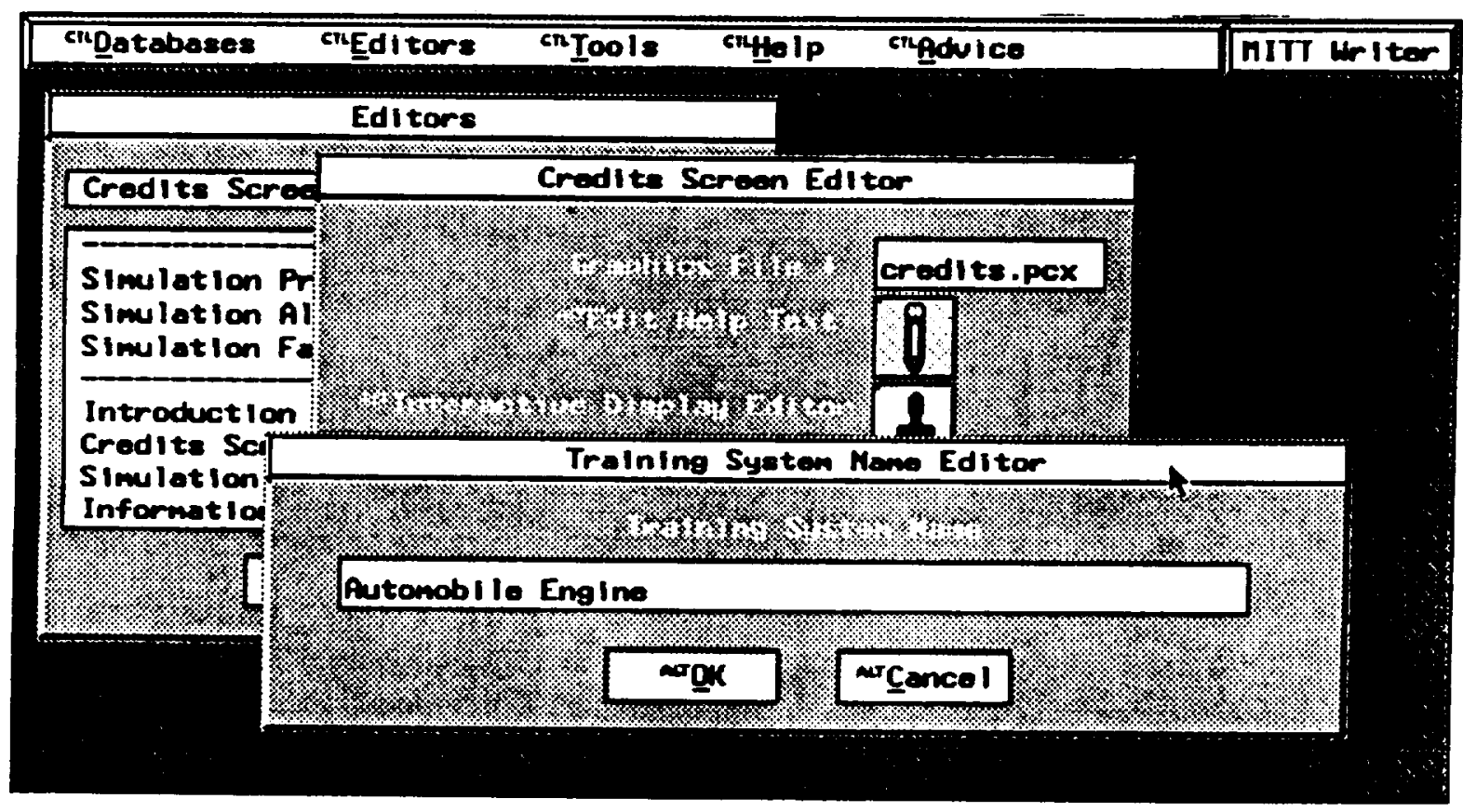

Figure 7. A Stack of Object Editor Windows. 


\subsubsection{Interactive Display Editor}

MITT Writer provides tools for graphical screen composition and layout. For editing the Introduction Screen, Credits Screen, Information Screens, and Simulation Screens, MITT Writer provides the Interactive Display Editor (see Figure 8). MITT Writer does not support bit-mapped editing of graphics. As stated earlier, this function is left to commercial packages that can produce the necessary .PCX format image files (in EGA 16-color, 640×350 resolution).

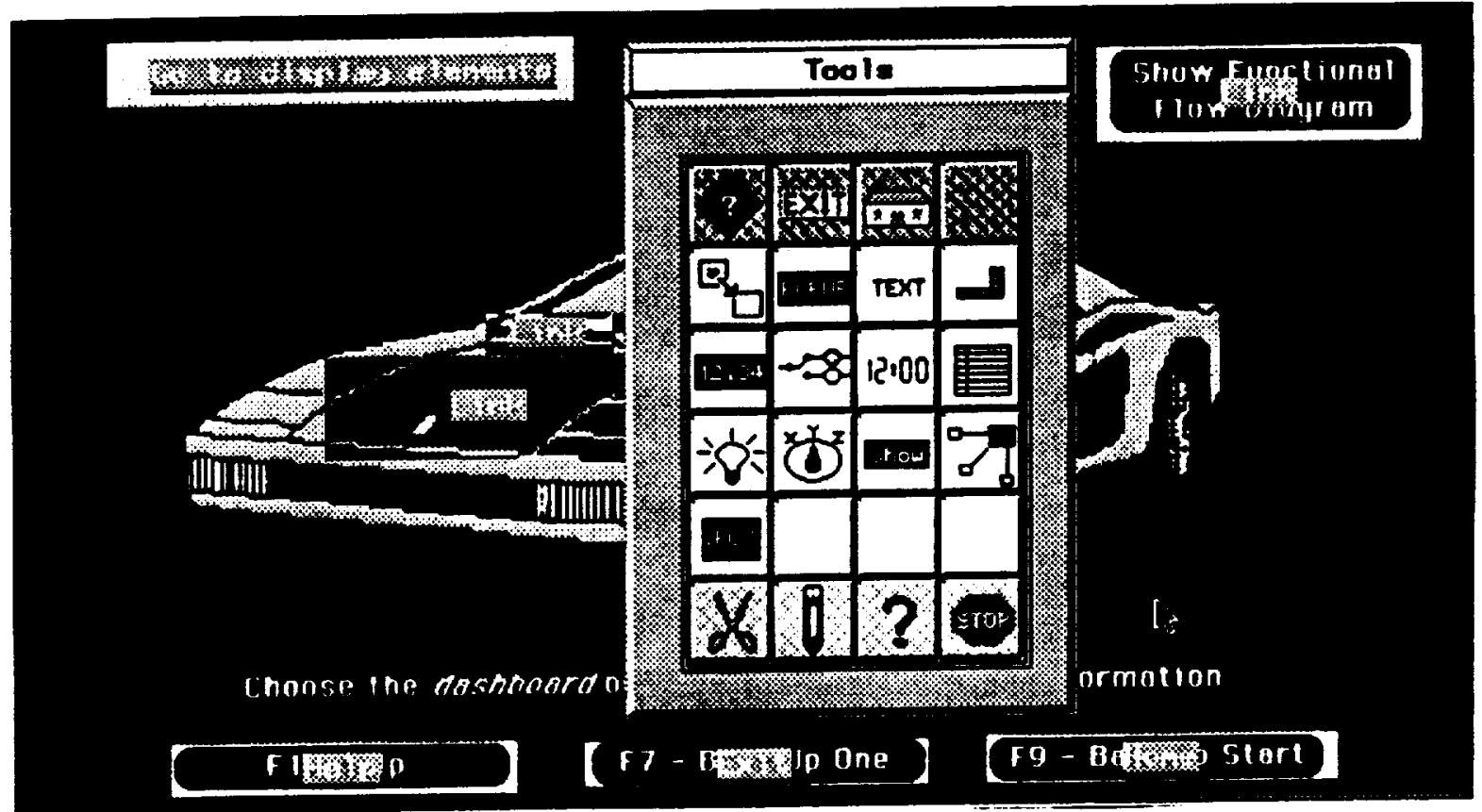

Figure 8. The Interactive Display Editor.

MITT Writer does, however, support the editing and manipulation of simulation- and instructionalspecific display sub-objects, such as data fields, text strings, "pop-up messages," and controls. Once authors have created these display sub-objects, they can then attach them to the underlying simulation. For example, by relating a display sub-object to a system sensor object, the display sub-object inherits the value of the sensor, subsequently displaying the sensor's value to the student. (By itself, a sensor object only contains the value of the sensor. It has no ability to show this value to the student.) In the case of data fields (see Figure 9), a data field will display the value of a sensor in numeric format as the simulation runs. In the case of status indicators, the status indicator will use the sensor value to determine a status messages to be shown to the student. 


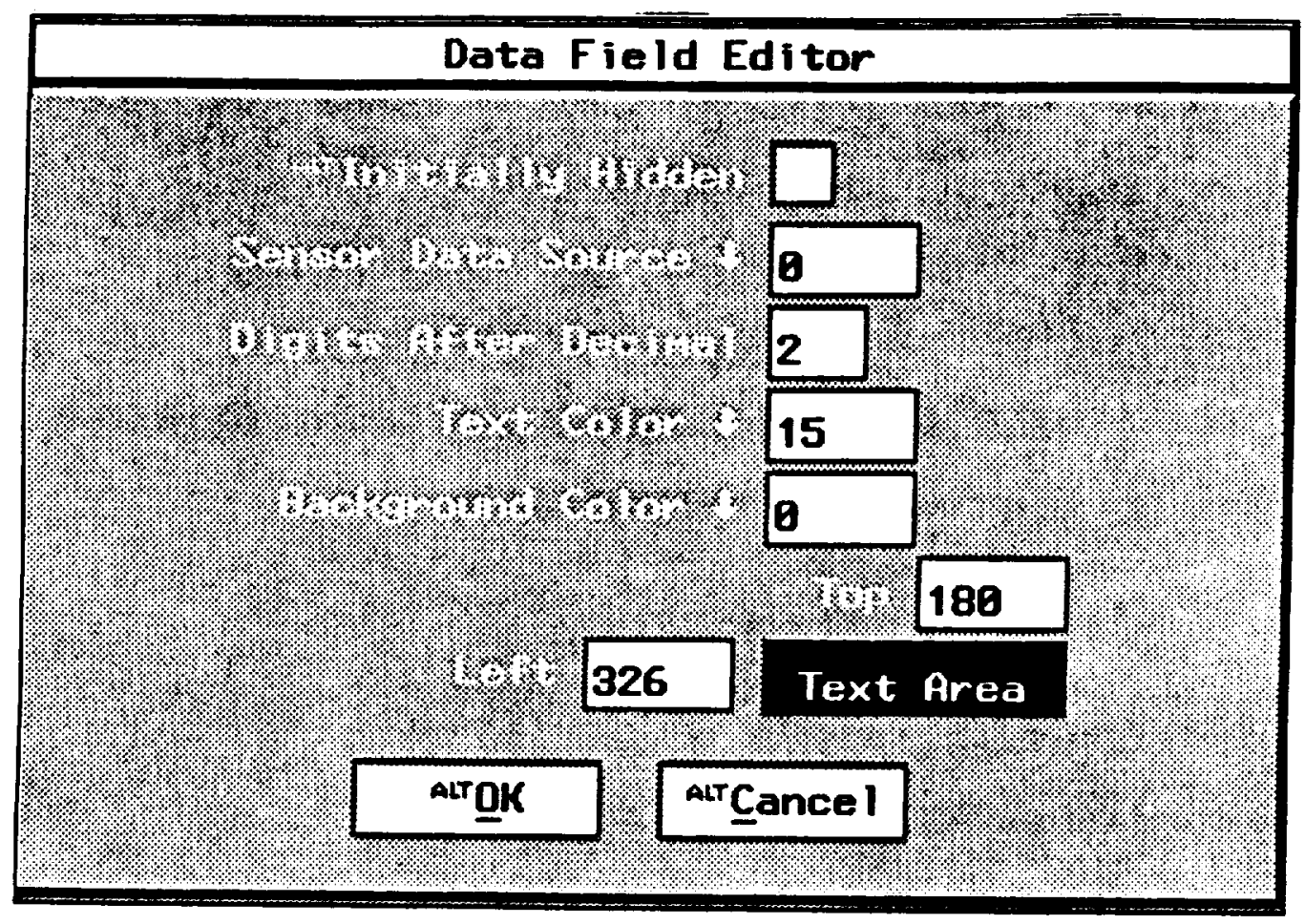

Figure 9. Data Field Editor.

\subsubsection{MITT Writer Advisor}

MITT Writer contains on-line, intelligent advice to guide new authors on the MITT development methodology. This methodology has been used over the past 5 years to develop new MITT rutors. The advisor was designed to minimize the amount of off-line instruction to learn the complex authoring process.

A backward-chaining expert system was used to capture this methodology. When an author asks for advice, the Advisor will review the current database, looking for incomplete work. If necessary, the Advisor will query the author for additional information or confirmation. After the review, the Advisor suggests the next action the author should perform, or the next object the author should create (see Figure 10). 


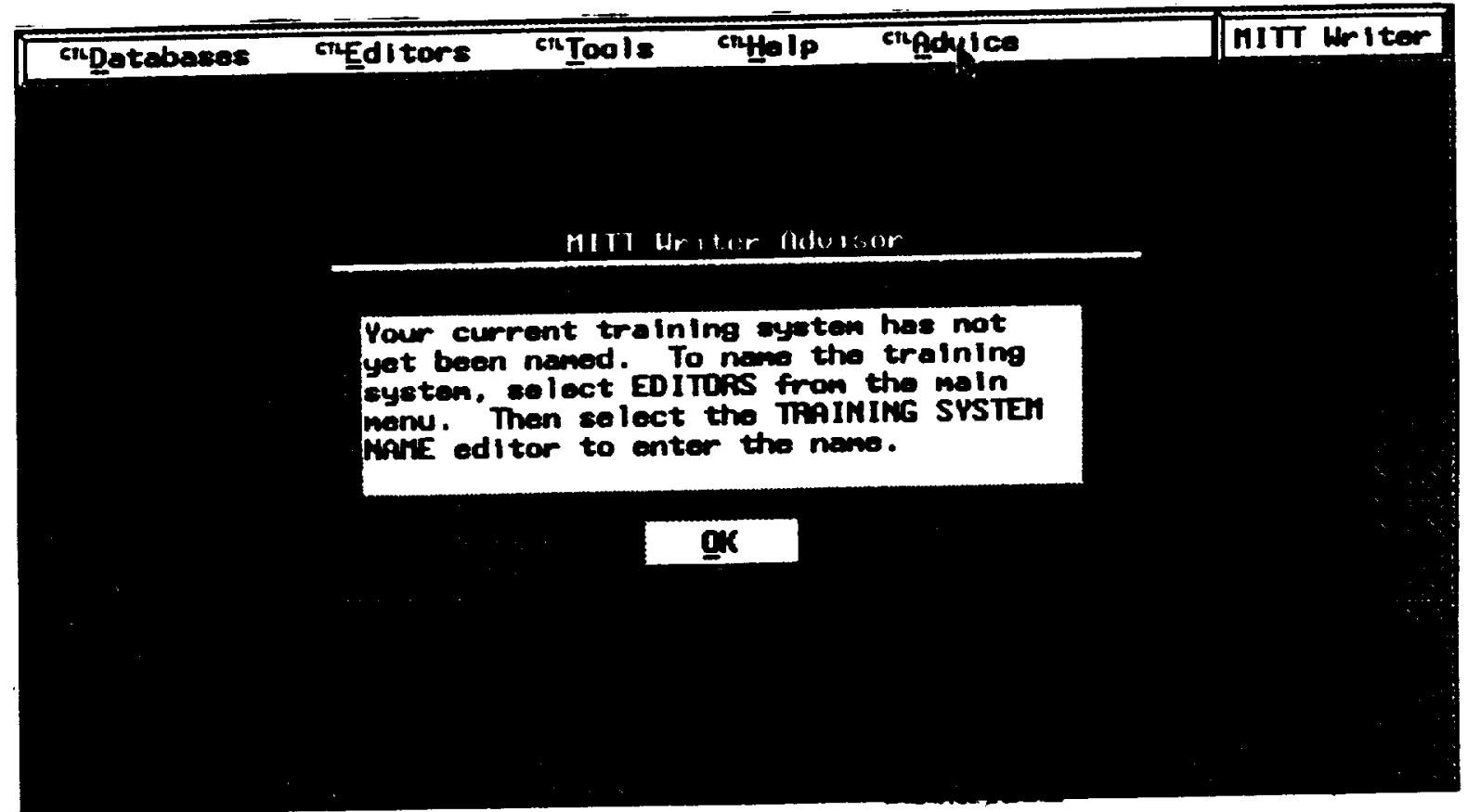

Figure 10. Sample Suggestion From MITT Writer Advisor.

\subsubsection{Help Library}

MITT Writer contains an extensive help library, including context-specific help (see Figure 11). At any point during a MITT Writer session, context-specific help is available to give the author information on the object currently being edited. The help library is arranged in a hierarchical fashion to support browsing by the author. At any entry in the library, the author is able to request more detail on the particular topic, or is able to get a more general level of help. The library holds most of the material contained in the MITT Writer User's Manual. In fact, due to the hierarchical structure of the library, the user's manual was automatically generated from the help library.

\subsubsection{Error and Consistency Checking}

MITT Writer provides on-line error checking for data correctness, completeness, and consistency. To ensure data correctness, validation is performed at the object level. Data that is invalid will be rejected and offered to the author for correction. To support completeness of the training system, the MITT Writer Advisor also checks the author's work. 


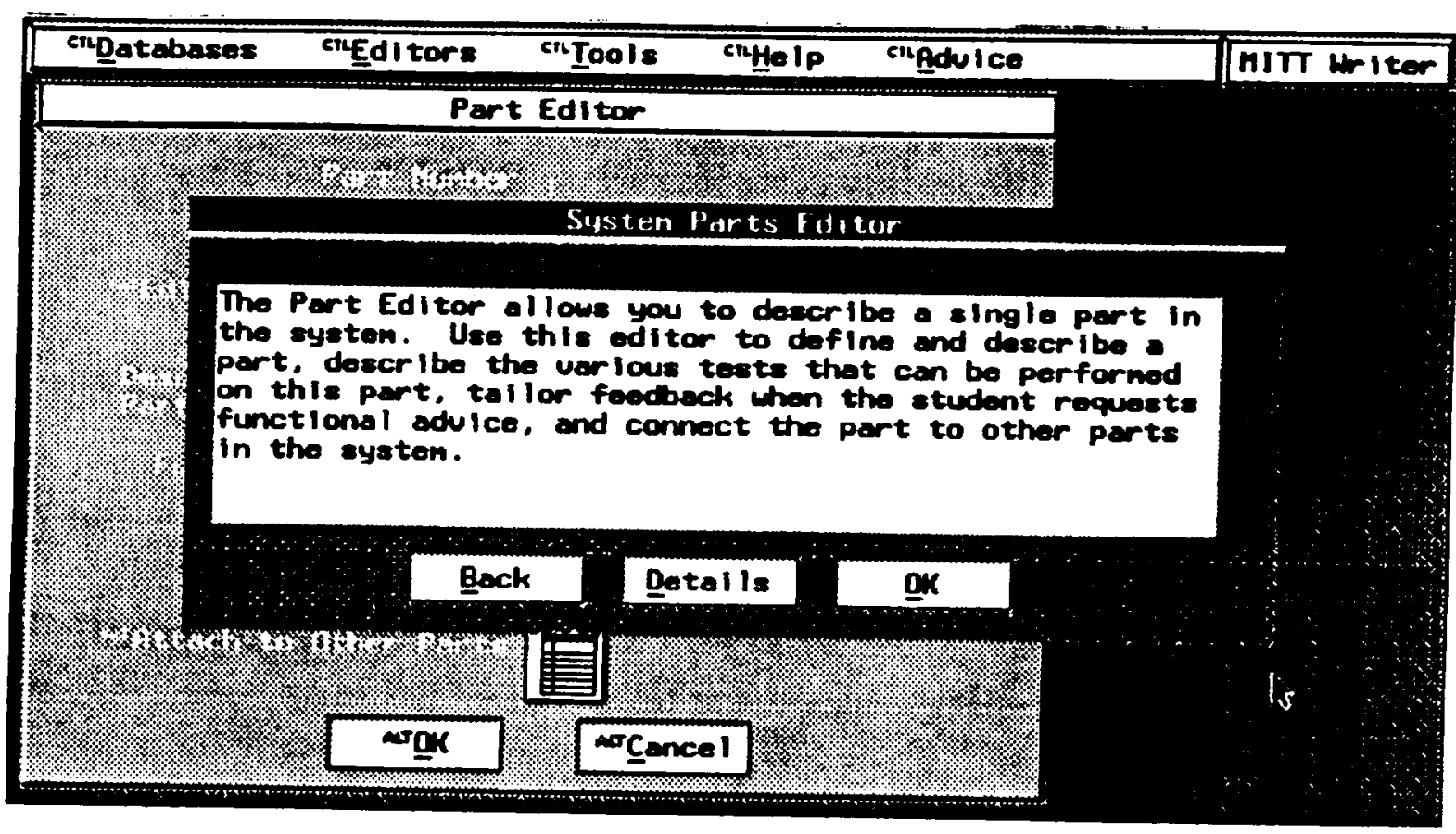

Figure 11. Sample Display from the MITT Writer Help Library.

To assure consistency between training system objects, MITT Writer provides a Consistency Check tool (see Figure 12). Inconsistencies occur in the database when objects reference missing objects or relationships. For example, while creating a new problem, the author might reference a procedure that has not yet been defined. The author intended to come back later and create the procedure. However, if the author forgets to create this procedure, then this 'dangling reference' will cause problems when the student attempts to run this problem. The Consistency Check tool will catch this error and present it to the author. (Note: In MITT Writer, the storage of this inconsistent reference to a procedure is not considered to be invalid. MITT Writer authors are allowed to complete their work and carry out their intentions, even though inconsistencies can occur as a result).

MITT Writer can not use an inconsistent database to create a MITT tutor. Before creating a tutor, MITT Writer checks the state of the database. If inconsistencies are found, the author is allowed to correct these errors before proceeding. 


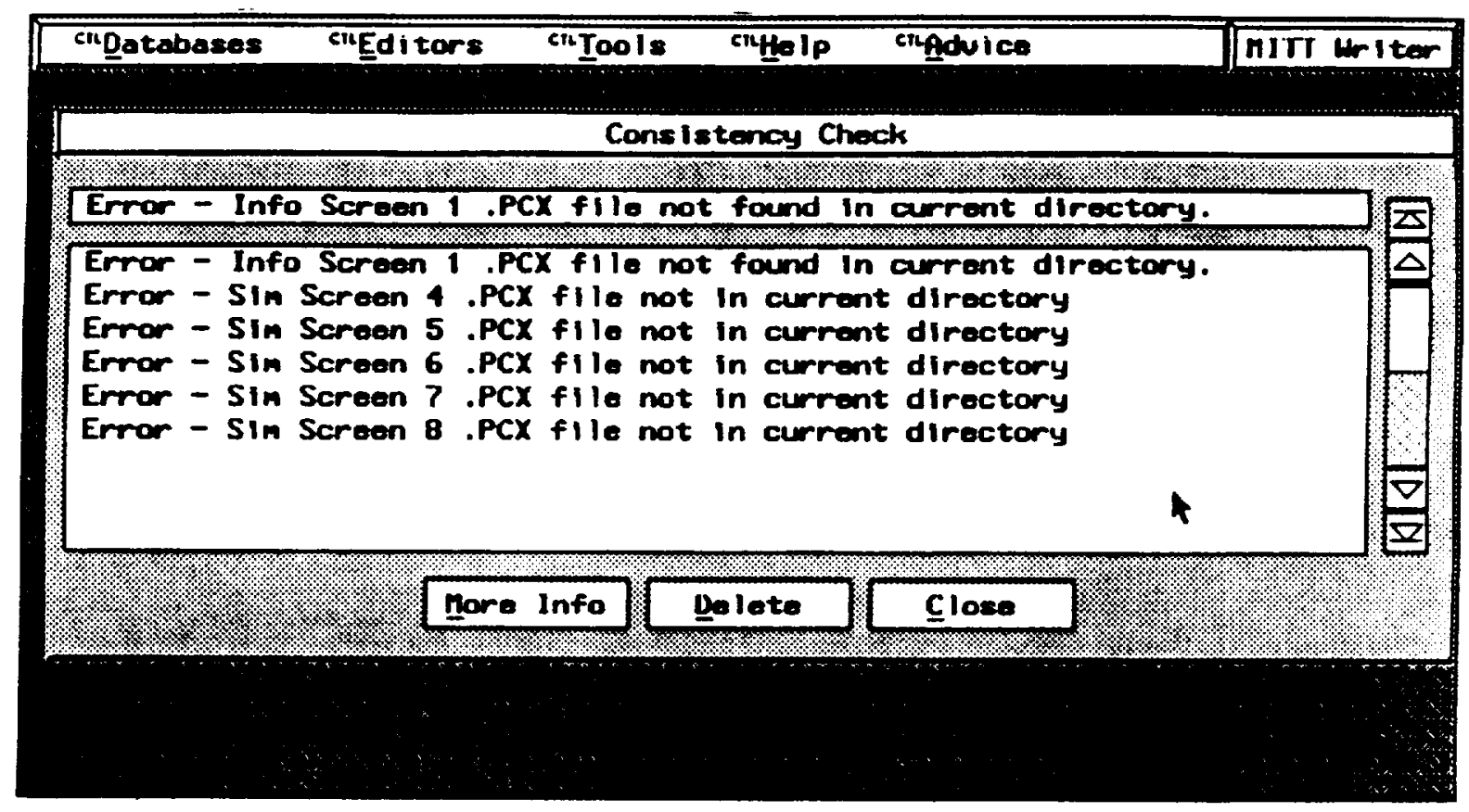

Figure 12. Sample Output from Consistency Check.

\subsubsection{Database Support}

MITT Writer authors save their work in databases, allowing them to continue development over several sessions. The development of a MITT tutor is a task requiring weeks, or even months, to complete. To support the author over these multiple work sessions, MITT Writer stores all work in databases which can be retrieved and modified at a later time. MITT Writer maintains information about the state of the database in a special database object. Example state information includes date and time of last modification, an indication of the results of the last consistency check, and database version number. MITT Writer uses this state information to prevent the author from closing a database without first saving changes, to prevent the author from creating tutors from incomplete databases, and to maintain database compatibility with future MITT Writer releases.

\subsection{The MITT Writer Authoring Process}

The MITT Writer author develops a new MITT tutor by first creating a base tutor, next testing this base tutor with MITT, and then successively refining the tutor by making additional modifications. In the past, MITT tutors were created by quickly developing the base tutor, demonstrating the tutor 
to potential instructors and students, and modifying the system based on their feedback. There were often multiple demonstration and feedback cycles during the development of a tutor. The development time for the base tutor is roughly equal to the time spent in modifying and retesting the tutor based on demonstration and feedback cycles. Figure 13 illustrates this development process.

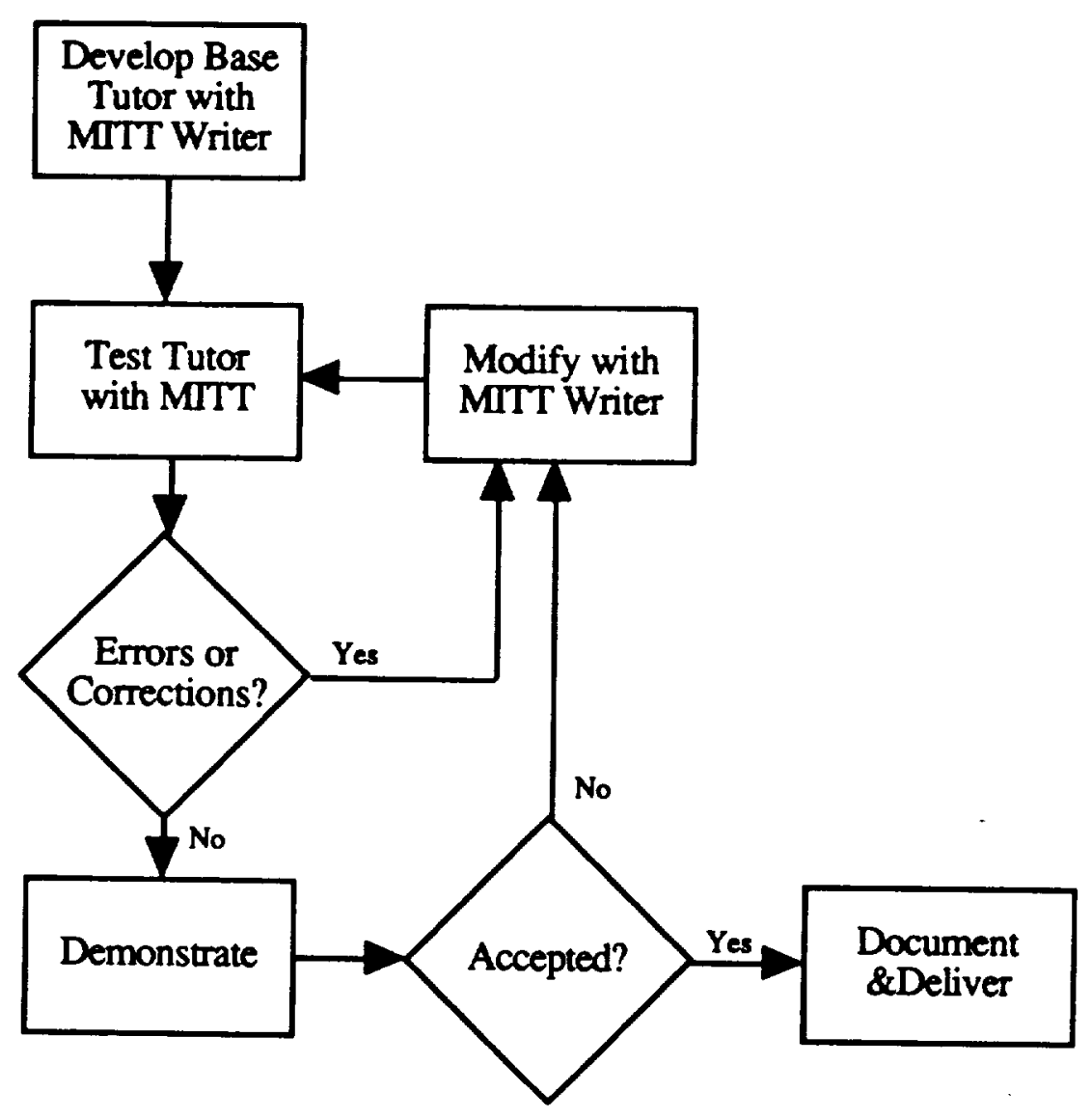

Figure 13. Overview of the MITT Writer Authoring Process.

\subsubsection{Creating the Base Tutor}

To create the base tutor, the author must pass through 5 major phases: 1) define functional characteristics, 2) create base simulation, 3) create the simulation interface, 4) develop instructional and procedural guidance, and 5) test and modify the system. Each of these phases is described below. 


\section{Define Functional Characteristics}

To define the functional characteristics for the tutor, the author must first define all components (i.e., parts and sensors) for the system. This process is greatly enhanced by first sketching a rough draft of the system functional flow diagram. The functional flow is simply a graphic representation of the system's parts and sensors that shows their functional dependencies.

For each part, the author describes the part, describes how the part can be tested, and relates this part to other parts in the system. For each sensor, the author must describe the sensor, describe how the sensor behaves under normal conditions, describe how the sensor can be tested, and indicate the part or functional relationship that the sensor detects.

This collection of parts, sensors, relationships, and detection points serves to teach the student the basic functional components and relationships of the system. The student is able to obtain information on the components, how these components are tested in the 'real-world,' and how these components are related to one another. The functional relationships also serve as a basis for the functional advisor in MTTT.

\section{Create Base Simulation}

To create the base simulation, the author must define how the system acts under both normal and failure conditions. Problems are based on the failure of a component in the system. When a component fails, the system behaves differently than it would behave under normal conditions. Sensor values change, tests on components reveal abnormalities, and faults occur in the system.

MITT depends on a surface-level simulation of the system. That is, MITT simulates the observable outputs of the system. This method of simulation is adequate and appropriate for the training that MITT presents.

To create the base simulation, the author begins by defining a problem to be presented to the student. The author defines the component that will fail, the procedure that will help the student diagnose the problem, and how the values of sensors react under the failure conditions. The author defines new sensor values and the time in the simulation that sensors are set to these new values. 
The author also defines faults and alarms that occur in the simulation. Faults occur when a sensor's value exceeds a predetermined range, or when a given period of time has elapsed. When a fault occurs, an associated audible and/or visual alarm is activated. These alarms are created by the author. (In MITT, faults do not cause components to fail, though this is a suitable enhancement for future versions of MITT and MITT Writer.)

\section{Create Simulation Interface}

In MITT, the student solves problems by performing tests, reading gauges and displays, and performing procedures. The simulation interface is a series of displays that allow the student to perform these actions. The simulation interface is made up of individual displays, display subobjects, and the relationship of these objects to the base simulation described above.

To create a simulation display, the author must first create the background graphic file for this display. This is accomplished using an external graphics package capable of producing .PCX format graphics files. The author then uses the Interactive Display Editor to place, or overlay, MITT Writer display objects on this graphic.

MITT Writer supports several type of display objects. Pop-up objects allow the author to show messages to students when they activate an area of the display. Text Strings allow the author to add text to the display. Data Fields allow the author to display the value of sensors in a numeric format. Status Indicators allow the author to present a text message based on the value of a sensor. Elow Regions allow the author to create simple animation of flow on the display. Eault Lists allow the author to display faults that have occurred in the system. Time of Day objects allow the author to display system time to the student. User Defined objects allow the author to display small graphics images based on the value of the sensor. Controls allow the author to simulate toggle switches, buttons, dials, etc., thus permitting the author to hide and show display objects. Show Begions allow the author to hide information until the student activates an area on the display. Links allow the student to move from one screen to another.

When appropriate, the author connects display objects to sensors in the base simulation. The connected display objects use the sensor values to display a number, message, or graphic to the student. 
-

- 


\section{Develop Instructional Guidance}

Instructional guidance falls into two categories: Procedures and Instructor Feedback. Procedures allow the author to guide the student through the diagnosis of a problem. The author may either generate one general procedure to guide the students through all problems, or generate a procedure specific to a given problem.

For each procedure, the author describes a series of steps that comprise the procedure. For each step, the author must describe to the student how this step should be performed, and relate this step to a student action (i.e., the author informs the student to view a sensor, test a part, or view a simulation display to perform the step). MITT uses these relationships to determine if the student has performed a step. For example, the author might determine that to perform step 3 of an engine diagnosis procedure, the student must view the value of the oil pressure sensor. The author relates this step to the oil pressure sensor. In MITT, the procedural expert uses these steps and relationships to determine when the student should perform the step, and to advise the student how to perform it.

The author can modify the Instructor Feedback component of MITT. Instructor feedback guides the student and points out features of MITT that the student might have overlooked. For example, the author might use instructor feedback to inform the student to request advice from the procedural expert (if the student has not used it during the current problem). Or, the author might also provide feedback to students if they attempt to answer the problem without gaining adequate information.

\section{Test and Modify System}

Once authors feel that the base system is complete and ready to test, various tools are available in MITT Writer to check the database and create the ITS files. The author uses the Advisor to check for completeness of the tutor. The Advisor informs the author of missing components that were overlooked. The author also uses the Consistency Check tool to check for inconsistent database references. The Consistency Check will present errors and wamings to the author. 
Once the database passes the advisor tests and consistency checks, the author creates the tutor by using the Write Training Files tool. When the author selects this tool, MTTT Writer will translate the database into the necessary ITS files.

The author then uses MITT to test the training files. In this mode, the author plays the part of the student: running problems, getting help and advice, viewing gauges and displays, and testing parts. In many cases, the author will notice errors and will note possible modifications to the tutor. In these situations, the author returns to MITT Writer, and makes the desired corrections.

\subsubsection{Demonstration and Modification}

After the author has created the base tutor, demonstration to outside parties (both instructors and students) is necessary to obtain additional perspectives on the design, useability, and acceptability of the tutor. In most cases, the initial demonstration of the system yields feedback that often points to critical modifications that need to be made to the tutor. These modifications often center upon the addition of functionality (e.g., more simulation screens, more parts and sensor points). When developing a MITT tutor, the author should plan on conducting multiple demonstration, evaluation, and modification cycles. As mentioned earlier, the time spent during these cycles is often equal to the time spent developing the base tutor.

\subsubsection{Delivery}

After developing the tutor, the MITT Writer author will deliver and distribute the new MITT training system. The author must first create the supporting documentation for the system. At a minimum, the author should create a student manual for the tutor. Template student manuals are provided to the author in the MITT Writer User's Manual, and on the MITT Writer distribution diskettes. The author modifies these templates by adding domain-specific information (e.g., functional flow diagrams).

MITT Writer supplies utility programs for 'bundling' the new MITT tutor. These tools aid the author in copying all of the necessary ITS and graphics files to distribution diskettes. The author delivers these diskettes, the MITT delivery diskette, and the newly created manual to prospective instructors and students. The author may choose to retain or distribute the authoring database Utility programs also exist to aid the author in this process. 


\subsection{MITT Writer Internal Architecture}

MITT Writer's internal architecture is depicted in Figure 14. There are 7 major components of the MITT Writer system: 1) the Display Manager, 2) the Database Manager, 3) Object Editors, 4) the Consistency Checker, 5) the Help System, 6) the Advice System, and 7) MITT File Support. Technical and implementation details for each of these components are discussed in this section.

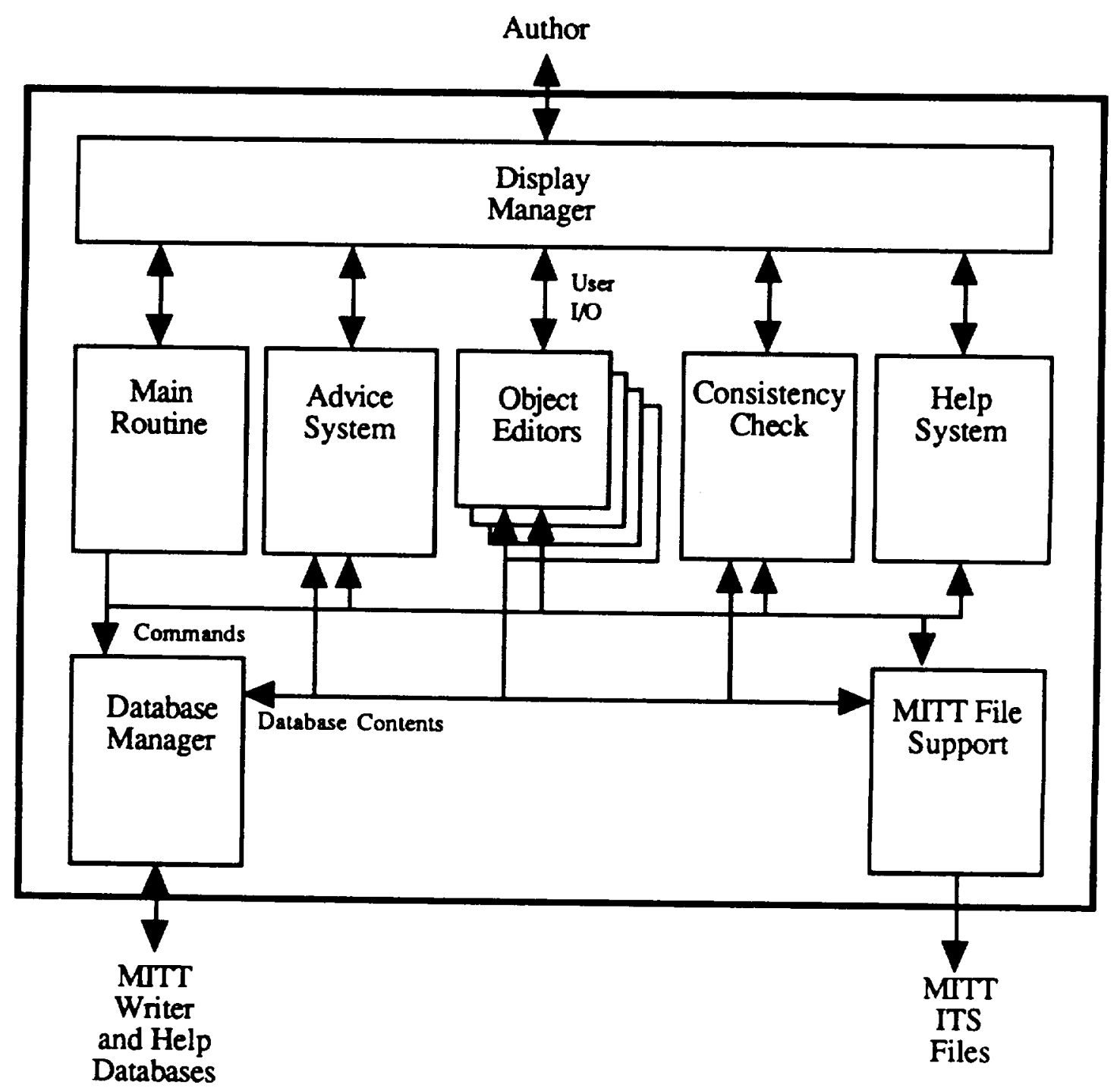

Figure 14. MITT Writer Internal Architecture. 
The Display Manager serves as an intermediary between the author and the MITT Writer system. The Display Manager is responsible for maintaining information about the display state of MITT Writer, opening and closing windows, and processing all author actions. The Display Manager centralizes all interface management routines.

The Display Manager was implemented using a message-passing design. When the author makes a gesture (i.e., moving the mouse, selecting a display item, pressing a key), the Display Manager first determines if the gesture should be handled by the Display Manager or by external routines. In the case of low-level gestures (e.g., moving the mouse), the Display Manager is capable of processing this gesture alone. However, in the case of high-level gestures (e.g., the user closing a window), the Display Manager must work with external routines to close the window, refresh the screen, and activate the next window. To do this, the Display Manager passes messages to the appropriate window(s), giving them instructions on what to do. (For example, in the case of closing an editor, the Display Manager must inform the editor to first save the object being edited, and to then close the editing form. The Display Manager then closes the window. The Display Manager next informs background windows to refresh their portion of the screen. Finally, an activate message is sent to the new top window, telling it that it is now active.)

To support the graphical interface, the Display Manager depends on two third-party graphical libraries. Low-level graphics are support by Metagraphics' Metawindows. High-level window, frame, and menu processing is supported by Ithaca Street Software's Menuet.

Because of the advanced functionality provided by the Display Manager, this component of MITT Writer consumes the most computing resources, both in storage (on disk and in memory) and in CPU cycles (for screen refreshes, message handling, etc.). The memory requirements for the Display Manager, along with those for the object editors, strained the $640 \mathrm{~K}$ memory limit on DOS. As a result, the Display Manager was heavily optimized during the later stages of MITT Writer development. 


\section{Object Editors}

From the MITT Writer author's point of view, the object editors provide the majority of the functionality provided by MIT Writer. These editors are the most heavily used components of the system. The basic design for each editor is that of a frame. The author is presented with the frame for an object, and is allowed to enter information into the structure. In the case of the Interactive Display Editor, this frame concept was augmented with direct-manipulation to relieve the author from having to understand the concepts of screen coordinates, and subsequently entering them into the frame for a display object.

The object editors interact heavily with both the Display Manager and with the Database Manager. The object editor is responsible for using the Display Manager to display object information on the screen. The object editor is also responsible for validating data before using the Database Manager to store the object in the database. Like the Display Manager, the object editors rely on the two graphics libraries to manage frames and manipulate graphic images.

\section{Database Manager}

The Database Manager was designed to support the permanent storage of objects and their relationships, and to maintain information about the state of the database in use. Components in MITT Writer communicate with the Database Manager via objects and functions. Objects are passed to and received from the Database Manager. Database Manager functions are available to control and manipulate these objects in the database.

In addition to the database used by the author, the Database Manager also controls the System Message database. The System Message database is used to hold all text necessary to support MITT Writer. Example text includes error messages, help text, and advice presented by the Advisor. These items are stored in an external database to conserve space in system memory.

MITT Writer components require both sequential and random access to the objects stored in the database. For example, the consistency check tool performs a sequential search on the database, looking at each object. Object editors, on the other hand, require random access based on an identification code for the object (e.g., part number). The Database Manager was designed to support both access methods. 
The Database Manager was implemented using a $B+t r e e$ as the file storage and indexing method. A commercial library, CBTREE by Peacock Systems, was used to support the low-level B+tree format. A network database structure was implemented on top of this format. This approach required minimal memory overhead, though the required disk space is comparable to that of commercial database management system (DBMS). Commercial DBMSs that support either network or relational models were considered, but memory considerations dictated against these alternatives.

\section{Consistency Checking}

The consistency checking tool scans the database and looks for references to missing objects. A list of inconsistencies is produced at the end of this scan. There are two levels of inconsistencies that can occur. Warnings are inconsistencies that degrade the operation of the tutor, but do not prove fatal. However, they should be corrected. For example, a simulation display may contain a link object that references itself (i.e., when the student activates this link, the same display is shown). MITT is able to handle these warning-level inconsistencies. Errors, on the other hand, are inconsistencies that prohibit the MITT tutor from operating properly. For example, a functional connection leading to a missing part will cause the MITT functional advisor to give improper advice. MITT Writer tags these types of inconsistencies as errors.

In addition to maintaining a list of inconsistencies in the current database, the consistency checking tool also provides additional details for each inconsistency. If authors wish to see additional information regarding an inconsistency, they select that inconsistency and ask for more information. The consistency check tool then provides additional details and offers advice on how to correct the inconsistency.

\section{Help System}

As mentioned earlier, help text is stored in the System Message database. In addition to storing individual help entries, the database also stores the relationships between these help entries. These relationships allow the author to browse through the help database, getting either a more detailed or more general level of help for a given entry. 
The help system contains both orientation help (e.g., how to use MTTT Writer) and contextspecific help (e.g., how to enter data into the current object editor). Context-specific help is supported by tagging each object editor with the identification code of the corresponding help entry. When the author asks for help, the help system presents this entry. This same concept could be extended to individual object components, though this was not done in MITT Writer.

To generate the MITT Writer User's Manual, a program was written to print out the contents of the help database. Given a starting entry, the program traversed the database structure, formatted, and printed the manual to disk. Figures were then added to this file. Using this technique, future changes to the help database can be easily reflected in the user's manual.

\section{Advice System}

MITT Writer contains an embedded expert system that guides the author through the MITT Writer authoring process. To develop this advisor, a prototype version was implemented using the CLIPS expert system shell. The expert system is implemented as a backward-chaining system, with the advisor attempting to assert that the database in question is complete. The MTTT authoring methodology and previous experiences in developing MITT tutors served to support the creation of the initial rulebase. After review and modification of the CLIPS version, the system was converted to a C-language based system. Again, memory constraints dictated this approach.

As the MITT Writer Advisor runs, it scans the appropriate sections of the database (as dictated by the rules). The advisor also queries the author to gather information that cannot be inferred from the database. When the advisor reaches a point at which it cannot continue, it offers the advice associated with the expert system's current sub-goal. For example, if the advisor is trying to reach the sub-goal of "All parts defined," then the fact that there are no parts in the system will generate an advisor message. Similar to the help system, the advisor retrieves necessary messages from the System Message database.

\section{MITT File Support}

The MITT File Support component of MITT Writer translates an author's database into a format suitable for MITT. Translation is necessary because of the different file formats required by the 
MITT tutor verses those required by MITT Writer. A database that has passed the consistency check with no errors is eligible for translation.

To translate the database, the MITT File Support component creates each file needed by MITT on an individual basis. The database is both randomly and sequentially read during translation. Disk I/O requirements for the translator are extensive, contributing to excessive execution time for this tool. Modifications were made to reduce the number of disk reads. In addition, to appease the waiting author, an estimation of "percent complete" is displayed during translation.

\subsection{Development of MITT Writer}

The MITT Writer Development project spanned 15 months, and focused on two major tasks. In one task, the existing MITT Fuel Cell Tutor had to be modified to create a generic training system shell that could be used with any domain. This involved examining the code for items that, if changed, would allow the software to represent a new domain. Data files were defined for these items. The MITT software was then modified to read these files and present the prescribed training.

The other major task involved designing and implementing the MITT Writer system. From the start, previous experiences in developing other DOS-based systems led us to believe that MITT Writer would challenge the capabilities and resources of the target computing platform. Subsequently, the technical approach to the design of MTT Writer focused on maintaining desired functionality while conserving computing resources. This became a critical issue when choosing a development language, surveying third-party software, and developing code.

During development, the early versions of MITT Writer and MITT were to support the development of the Minuteman Missile Message Processing Tutor (described in Section 5.1). As such, early emphasis in the project was directed at making MITT as generic and file-driven as possible to support this new domain. Early versions of MITT Writer's file generation capabilities were used to create these new files.

Early MITT Writer development focused on designing and implementing the Display Manager and Database Manager. The majority of the Object Editors were added next. To complete the base 
MITT Writer system, the Consistency Check tool and complete file translation capabilities were added. Also during this period, enhancements were being incorporated into MITT, such as optimizing the procedural expert, embellishing portions of the student interface, and implementing support for additional display objects.

The base MITT Writer system was demonstrated in October, 1990. During this demonstration, a sample database was modified, checked for consistency, and translated into MITT ITS files. The MITT software then used these files to present the modified training.

Between October, 1990 and February, 1991, the consistency check system was enhanced, and the MITT Writer Advisor and Help System were incorporated. The MITT code continued to improve, as support for user-defined objects and controls was implemented. In addition, significant improvements were made in the student interface and simulation control functions.

The MITT Writer and MITT systems were first used by outside parties during the MITT Writer Workshop (see Section 5.2), held in early February, 1991. This two-day workshop allowed the participants to use MITT Writer to modify an existing tutor and test their modifications using MITT. Suggested interface enhancements and programming changes were collected during the workshop. These suggestions were prioritized and used to guide the final development.

During late February and March, 1991, the MITT and MITT Writer systems were completed and delivered in April, 1991. The two existing user's manuals were updated, combined, and delivered during this period also. 


\subsection{MITT Writer Advanced Development}

\subsection{Minuteman Missile Message Processing Tutor}

The first part of the Advanced Development project used the Microcomputer Intelligence for Technical Training (MITT) paradigm to develop an Intelligent Tutoring System (ITS) for an operational training unit of the Air Force Air Training Command (ATC). The domain was identified as the Message Processing System for the Minuteman missile. Galaxy Scientific personnel worked closely with personnel from Chanute Technical Training Center to develop the system.

The Message Processing System for the Minuteman Missile involves data communications within a network of launch facilities and launch control facilities. A message enters the site through a hardened cable, is processed through various communications drawers, and is passed on to other sites, as shown in Figure 15. The Missile student must ensure that this signal is valid upon entering the site, is processed properly, and is routed to the next site.

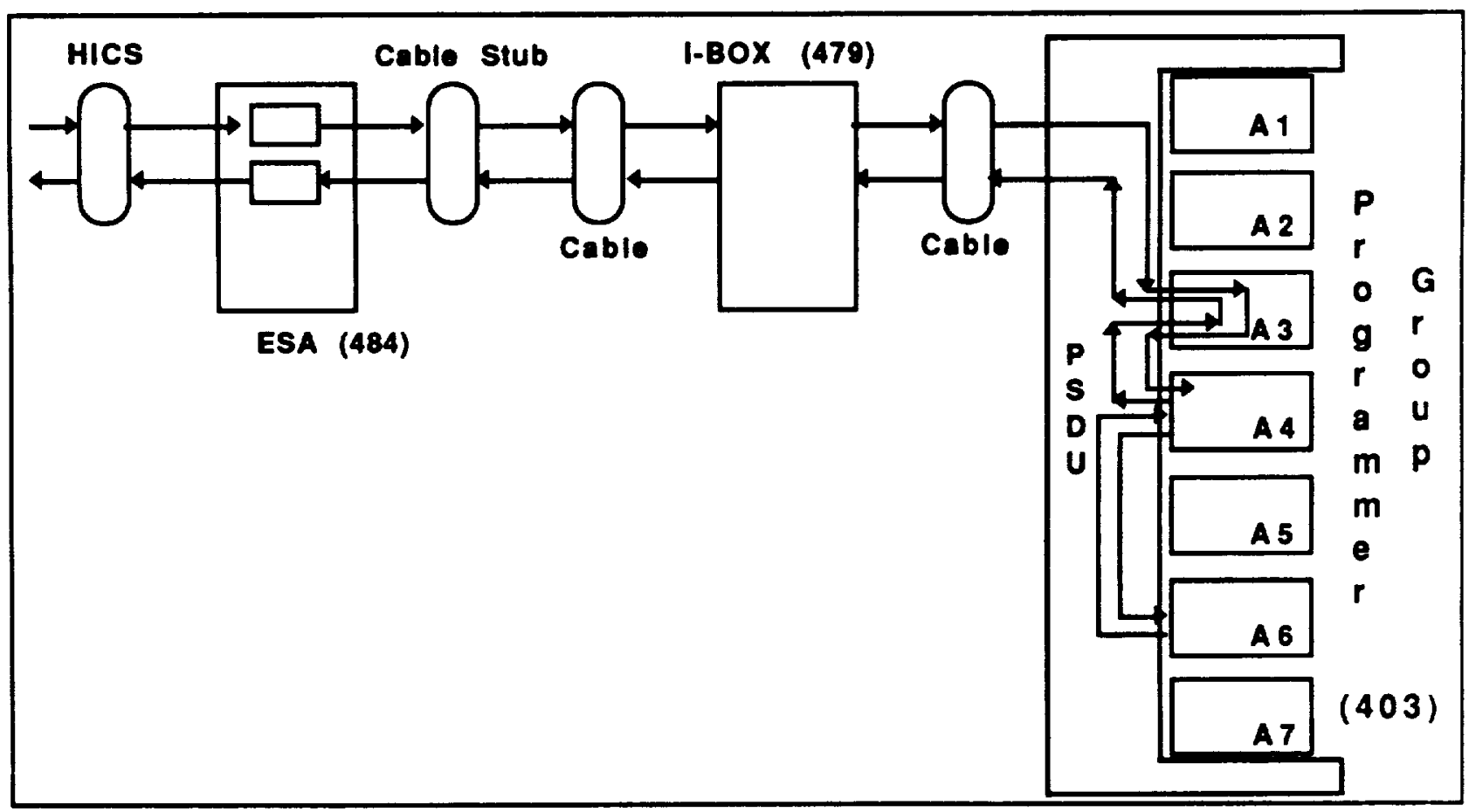

Figure 15. Missile Tutor Overview. 


\subsubsection{Fuel Cell vs. Message Processing}

The original design of MITT (developed in cooperation with NASA) was shaped by the Electrical Power System (Fuel Cell) on the Space Shuttle. The Fuel Cell had many properties that heavily influenced MITT's capability. This section will compare these properties with the properties exhibited by the Message Processing System and explain how the differences were accommodated.

\section{Gauges}

The first difference involves how data is presented to the student in each system. The Fuel Cell presents many video displays and gauges to the astronauts and flight controllers. To receive information about the system, the astronaut only has to look at a display or gauge. In contrast, the Message Processing System has very few instruments, but continuously presents data to the student. The Missile student is forced to decide not only what equipment to look at, but also how to look at the equipment.

For example, if astronauts suspect trouble with the Fuel Pump, they simply look at one of the displays or gauges to check the value. In contrast, if a Missile student suspects trouble with a drawer, they must remove a connector and attach a piece of monitoring equipment (a headphone or volt meter). This demands a much more active role on the part of the Missile student, which in turn creates greater software requirements.

\section{Data Entry Support}

This more active role requires that the Missile student not only choose the component to inspect, but it also requires that the student choose the monitoring equipment and how and where to attach it. As a result, the simple Fuel Cell gauge interface had to evolve to support this more dynamic data entry procedure.

An example scenario will help to explain the data entry procedure. The Missile student monitors equipment in several different ways. Assume that the system contains only four pieces of equipment: Drawer A, Drawer B, Drawer C, Drawer D. Also assume that only four tests are available to monitor the equipment: Test 1 , Test 2 , Test 3 , and Test 4 . A realistic scenario would allow the student to perform each test on each drawer. This requires support of 16 different tests 
for this small example. If each test required that the student identify two different pins on each drawer for each test, the number of actions that must be supported would grow exponentially.

If a programmer were modifying the system to support this, the programmer could use very specific statements, similar to the following:

"If Test $=1$, Drawer $=\mathrm{C}$ and Pins $=2,5$ then display a data value of +12 Volts".

However, to support this kind of logic in an authoring system requires the development of a scripting language. The authoring system for MITT does not support scripting, so another solution had to be used.

\section{State Machine over Scripting Language}

The solution treats the system as a state machine. Each screen that the student sees represents a certain state. For example, the fact that the student sees Screen 2.3, implies that the student has already seen Screens 2.1 and 2.2. This state machine eliminates the need to keep track of global variable such as Test, Drawer and Pins.

The basic MITT "Gauges" interface could support this more dynamic data entry procedure, but at a cost. This cost was on memory and data size. As mentioned before, each state of the system must be represented by the system. Since the combinations of equipment, tests and pins is rather large, the amount of data required to represent this is also large. However, this approach agreed with the MITT Writer Authoring System design.

\section{Procedures}

The level of detail required to represent procedures (not procedural advice) differs between the Fuel Cell and the Missile Tutors. In the Fuel Cell, the astronaut only needed to know which procedure needed to be performed. The details of how to perform the given procedure were not important. The astronaut merely chose an item from a list of procedures.

In contrast, the Missile student was concerned with identification of the correct procedure, as well as exactly how to perform the procedure. To do this, the Missile student was required to select the procedure to perform, the piece of equipment on which to perform the procedure, and the pins to 
which to connect the test device. The last of these steps is shown in Figure 16. Therefore, as previously stated, a more active role was required of the Missile student than of the astronaut.

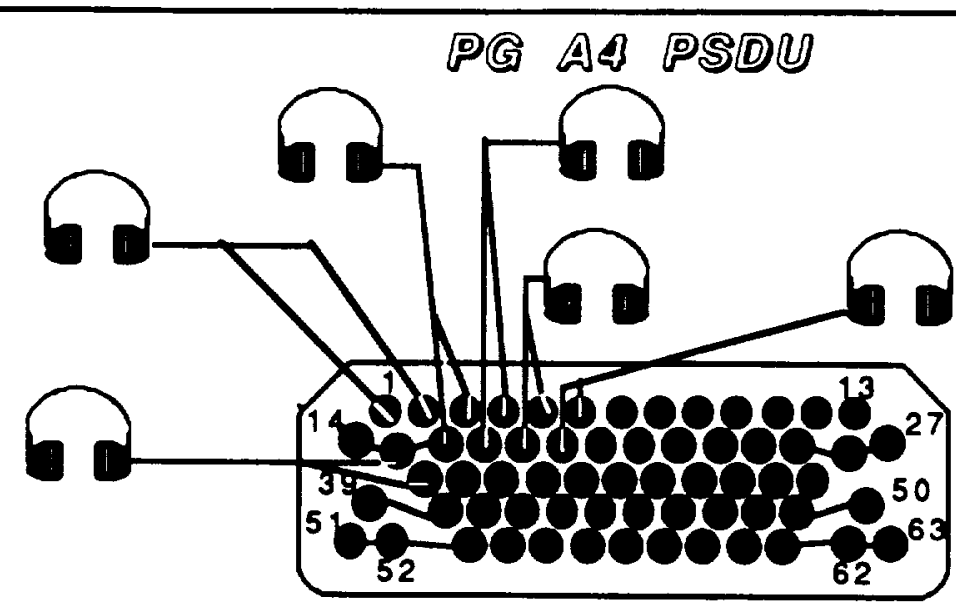

J24

Choose headphones to listen for tone ... F1- Holp F7 - Back Up One F9 - Back to Start

Figure 16. Missile Tutor Display.

Interface Suggestions

As suggested by the intensive nature of data entry, the data entry portion of the Missile system (Procedures/Indications selection from the Options Menu) becomes the primary focus of the system. This emphasizes the procedures and de-emphasizes the use of the functional flow of the system. ATC personnel suggested that the primary screen be the Procedures/Indications screen and that the other functions that exist on the current options menu be included in a "help" key. An answer button could also be added on the main screen. The "help" function would then list Functional advice, Procedural advice, remaining parts, and information and description functions.

While this addition seems to make sense for this domain, it is questionable whether it would make sense for all domains. Also the de-emphasis on the functional flow is not desirable. However, the MITT tutor was enhanced to appear less text-based and more graphical. 


\subsubsection{MITT Writer and MITT}

As mentioned earlier, the Missile system was designed with MITT Writer in mind. Every effort was made to guide the Missile design to be compatible with MITT Writer. Occasionally, the Missile system development uncovered some MITT Writer design deficiencies.

The Missile system was developed by programs to generate the files that MITT reads. Even though MITT Writer was not mature enough to support the full development of the Missile system, the Missile system required only the following three custom software changes of MITT:

- $\quad$ removed the sensors from the feasible set because sensors are only used as data sources, not components for the Missile System

- $\quad$ suppressed some facts from being asserted in CLIPS to conserve memory

- changed the options menu from "Gauges G" to "Procedures/Indications N"

The Missile domain was a very challenging one. It required extensive analysis and planning to incorporate the Missile system into the existing design. ATC personnel also pointed out several areas where the design of the MITT interface could be changed to make more sense in the new Procedures/Indications context. While certain limitations were identified, the Missile Tutor helped demonstrate that the MITT design was robust enough to support another technical training domain.

\subsection{MITT Writer Workshop}

The MITT Writer workshop was held on February 7 \& 8, 1991 in Atlanta, GA (Browning, et al., 1991). The workshop spanned two days for a period of approximately 14 hours. Eighteen people from the Air Force, Navy, and NASA attended the workshop. The workshop was supported by 5 Galaxy Scientific personnel.

The workshop had the following goals:

- to provide an initial test of MITT Writer usability

- to teach participants to use the authoring system

- $\quad$ to prompt ideas for subsequent MITT Writer workshops 


\subsubsection{Workshop Format}

The workshop consisted of both formal presentations and extensive laboratory exercises. The formal presentations addressed a variety of concepts, including functional flow, problems, faults, alarms, display elements, and procedural editors. After each formal presentation, the groups were given directed exercises to complete. The participants were divided into small groups (3 people/group) for the laboratory exercises.

The demonstration system for the workshop was an Automobile Engine Tutor. The participants were given a tutor with portions omitted. The exercises were designed to aid users in completing the tutor. Also, each group was encouraged to customize their Automobile tutor.

Upon completion of the workshop, participants were asked to evaluate MITT Writer by completing a four-page questionnaire. The questionnaire covered three major topic areas: the workshop, MITT, and MITT Writer. The following section reports the results of the evaluation.

\subsubsection{Evaluation Results}

Fourteen evaluation forms were returned at the end of the workshop. Respondents were asked to rate certain factors, using a 5-point scale: Excellent (5) to Unacceptable (1). The results from the major categories (Workshop, MITT, and MITT Writer) are summarized in Figure 17. Each of categories received very high marks on the five-point scale. These average ratings are discussed below.

Without exception, the questionnaire respondents found the MITT training system easy to use (see Figure 18). When assistance or explanation was needed, the on-line help was available and useful. Respondents were very satisfied with the graphical appeal, clarity, and intuitive nature of MITT.

Respondents also liked MITT Writer (see Figure 19). The system has sufficient on-line help and advice to support the powerful authoring environment. Correspondingly, the highest rating on the evaluation was $4.8 / 5.0$ for the MITT Writer on-line help. 


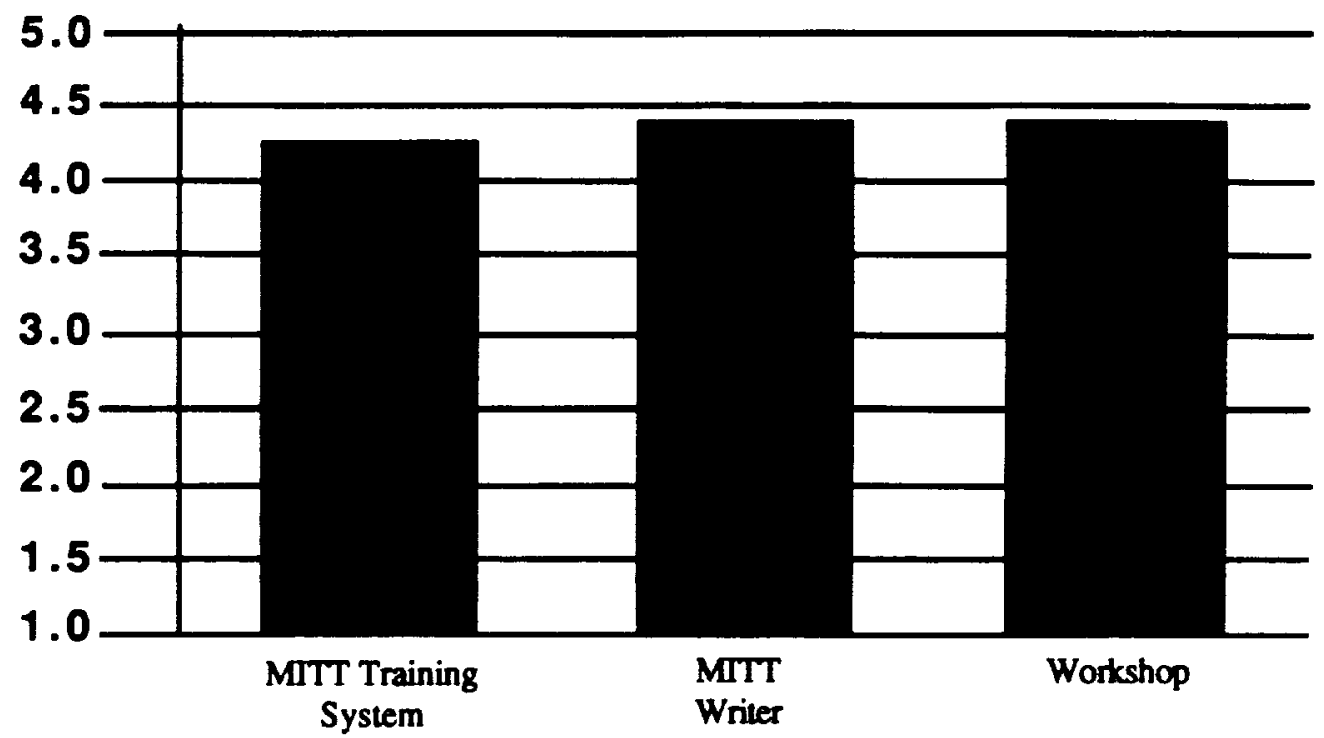

Figure 17. Average Ratings on Major Categories.

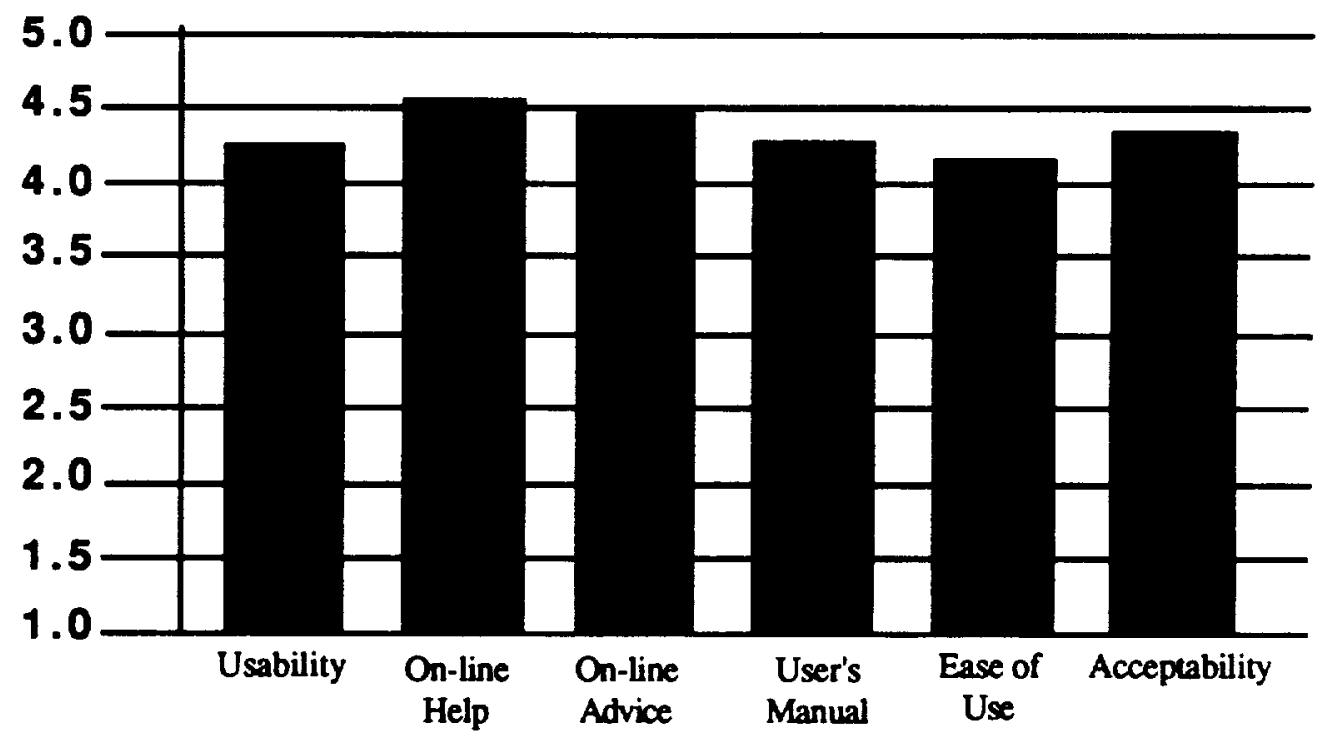

Figure 18. MITT Training System Scores - Overall. 


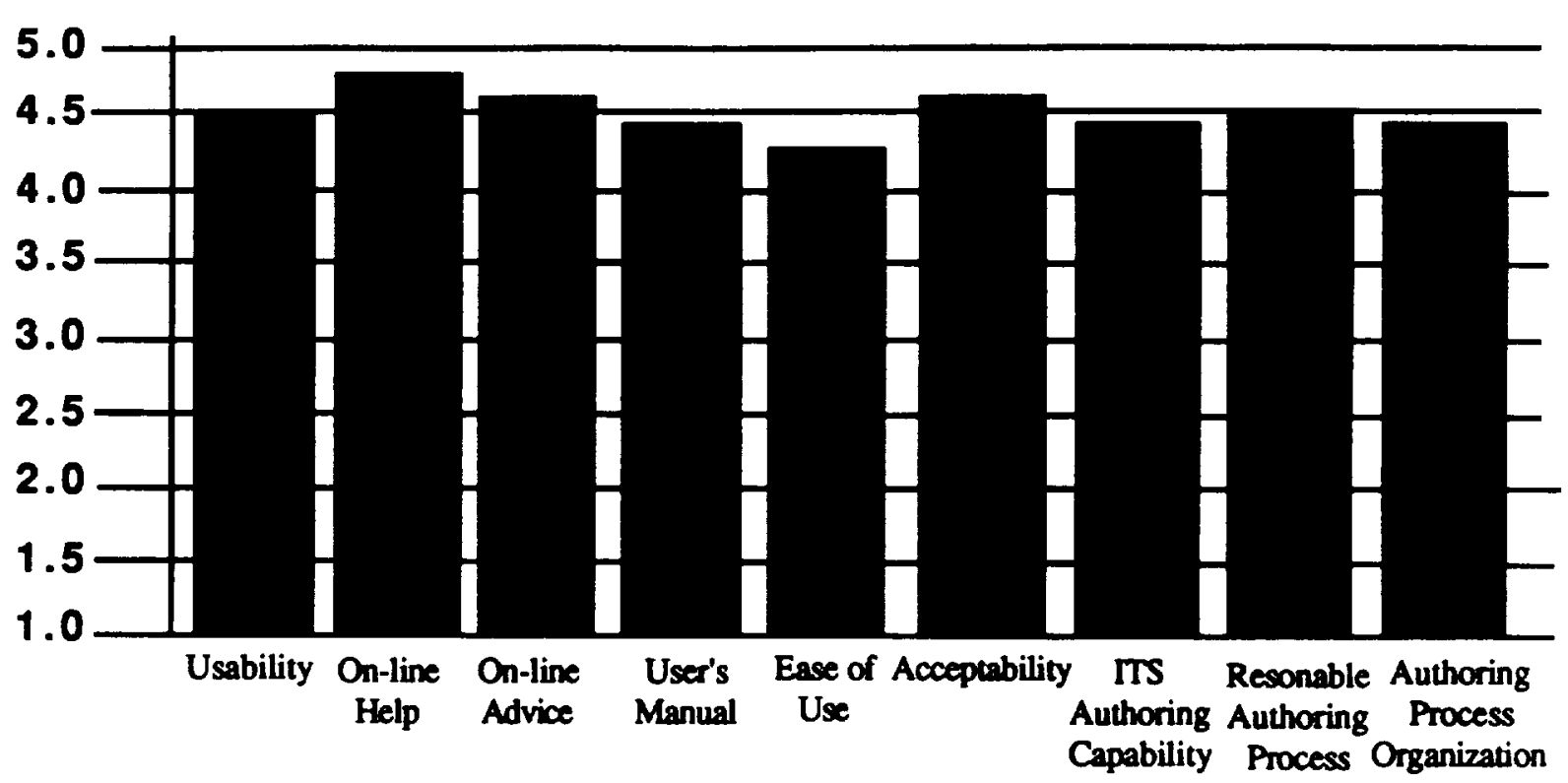

Figure 19. MITT Writer Ratings - Overall.

Overall the workshop was a success (see Figure 20). The workshop met the expectations of all respondents. However, a majority of the respondents were not completely satisfied with the length of the workshop. Two days did not seem to be long enough. As a result, this category received the lowest rating on the questionnaire - 3.9/5.0. Even though this falls in the "Good" range, it is noteworthy when planning the next series of authoring system workshops.

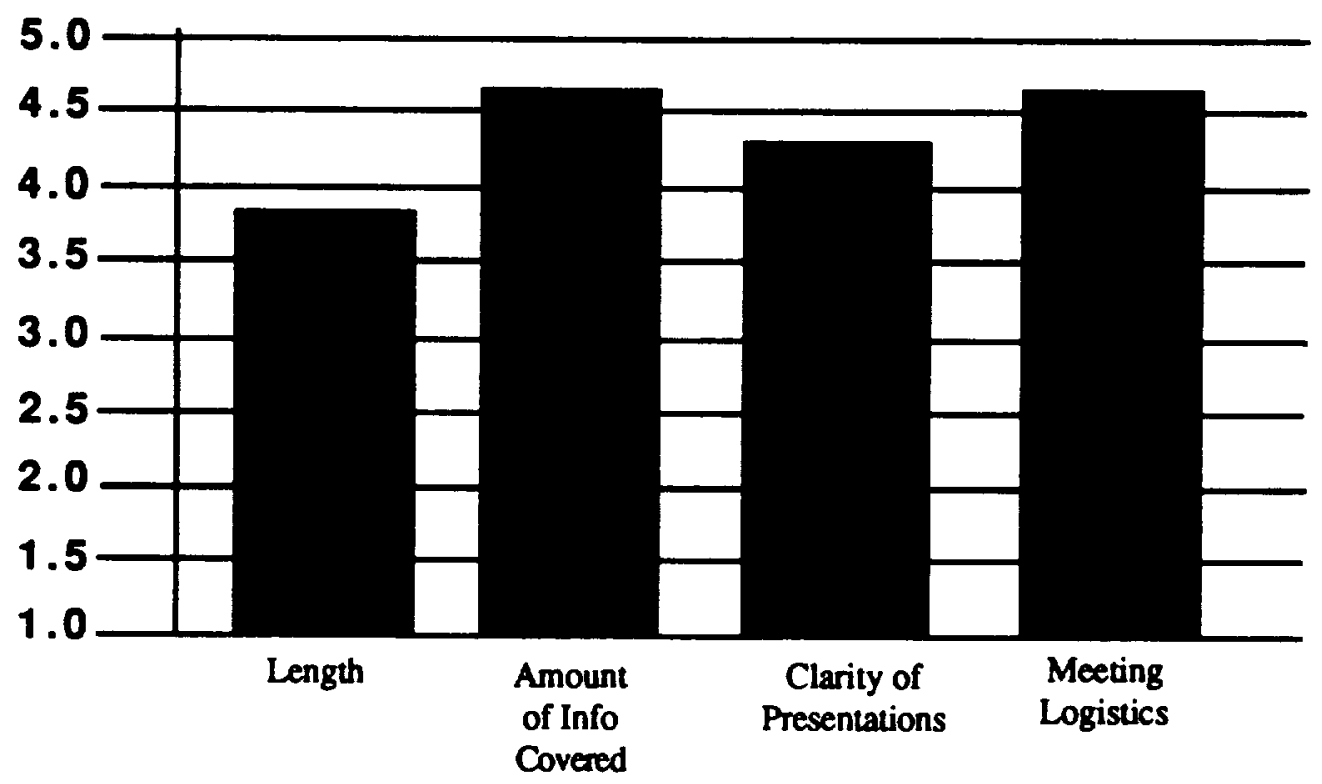

Figure 20. Workshop Ratings. 


\subsection{Summary and Areas for Future Development}

\subsection{Summary}

The MITT and MITT Writer systems are a reasonable alternative for simulation-based diagnostic training. MITT tutors operate on computer systems that are already installed in training installations. MITT tutors provide challenging, simulation-based problems to students. MITT delivers this training to students using ITS technology. MITT presents problems, monitors student performance, compares student actions to expert actions, and presents suitable feedback to the student.

MITT Writer provides economical development and maintenance costs for these training systems. MITT Writer supports instructors and subject matter experts, rather than programmers, in developing MITT tutors. MITT Writer provides enhanced ITS authoring capabilities and allows the author to rapidly develop and maintain MITT tutors. The MITT Writer authoring environment guides technical personnel to organize their knowledge in a format that is aligned with the MITT architecture, and based on the workshop results, is relatively easy to use.

Overall the workshop was a success. The workshop met the expectations of all respondents. Without exception, the evaluation respondents found the MITT training system easy to use. Respondents were very satisfied with the graphical appeal, clarity, and intuitive nature of MITT. The respondents indicated an acceptance of MITT Writer's ITS authoring capability. The respondents found that MITT Writer has sufficient on-line help and advice to support the powerful authoring environment. They also indicated that the MITT Writer authoring process was both reasonable and properly organized.

The Missile domain required extensive analysis and planning to incorporate the Missile system into the existing MITT design. ATC personnel pointed out areas where the design of the MITT interface could be changed to accommodate the domain's emphasis on procedures. While certain limitations were identified, the Missile Tutor demonstrated that the MITT design is robust enough to support a variety of technical training domains. 


\subsection{Areas for Future Development}

MITT and MITT Writer present a promising approach to the development of technical training. In the near future, enhancements can be made that will increase the effectiveness of both the authoring environment and the training it supports. In addition, work can be conducted that will increase the use and acceptability of the MITT training approach.

Presently, another MITT Writer workshop is being planned to teach the use and application of MITT Writer for ATC. Additional workshops would aid in the transfer of the training technology to the User Commands. Both MITT and MITT Writer are being used to develop a new MITT tutor for Space Command. Based on this new MITT tutor, or other current MITT tutor projects under development at Armstrong Laboratory Human Resources Directorate Training Systems Division, a formal evaluation of training effectiveness and cost effectiveness could be conducted.

The current upgrade in the standard Air Force computing environment offers new opportunities to increase the functionality of both MITT Writer and MITT. From a training technology point of view, enhancements in student modeling and instructor guidance can be made to include additional diagnostic techniques and new uses for the student model (e.g., intelligent problem generation, increased explanations by the procedural expert). The simulation component of MITT could also be enhanced by creating deeper simulation models, intelligent on-line functional flow diagrams, and providing support for multiple component failures.

On the authoring side, additional objects (e.g., audio/video for information displays) and object editors (e.g., interactive functional flow editor) can be added. The capabilities of the procedure editor can be enhanced to support more robust procedures (e.g., include conditional branches).

The MITT and MITT Writer environments can be partially or wholly integrated to reduce the time necessary to test changes made to the training system. For example, "preview" tools can be added to allow the author to try out new procedures, view screens in the manner that students would view them, or test functional advice on newly modified functional flow networks.

Networking support can be added to allow for connectivity between multiple authors of a training system, or to allow connections between instructor and student. An instructional station 
component can be added to allow instructors to monitor a student's problem solving session, subsequently offering advice or manipulating the simulation.

MITT and MITT Writer were developed in the C programming language. As the tools prepare for transition into the Air Force training community, support for Ada versions may be required. Many of the suggested embellishments could be made during this translation process. 


\section{References}

Browning, E.J., Johnson, W.B., Wiederholt, B.J., Norton, J.E., and Morgan, C.S. (1991). Microcomputer Intelligence for Technical Training: Workshop Report and Software Completion Plan. Atlanta, GA: Galaxy Scientific Corporation.

Johnson, W.B. (1981). Computer simulations for fault diagnosis training: An empirical study of learning from simulation to live system performance. (Doctoral Dissertation, University of Illinois, 1981), (Dissertation Abstracts International, 41(11) 4625-A. (University Microfilms No. 8108555).

Johnson, W.B. (1987). Development and evaluation of simulation-oriented computer-based instruction for diagnostic training. In W.B. Rouse (Ed.), Advances in man-machine systems research: Vol. 3. Greenwich, CT: JAI Press, 99-125.

Johnson, W.B. (1988a). Developing expert system knowledge bases for technical training. In L.D. Massey, J. Psotka, and S.A. Mutter (Eds.), Intelligent Tutoring Systems: Lessons Learned (pp 83-92). Hillsdale, NJ: Lawrence Erlbaum Associates, Inc.

Johnson, W.B. (1988b). Intelligent tutoring systems: If they are such good ideas, why aren't there more of them. Proceedings of the 10th Annual InterservicelIndustry Training Systems Conference, Orlando, FL: The Industrial Security Association, 399-406.

Johnson, W.B. and Fath, J.L. (1983). Design and initial evaluation of a mixed-fidelity courseware for maintenance training. Proceedings of the 27th Annual Meeting of the Human Factors Society (pp 1017-1021). Norfolk, VA: Human Factors Society

Johnson, W.B. and Fath, J.L. (1984). Implementation of a mixed-fidelity approach to maintenance training (TR-661). Alexandria, VA: U.S. Army Research Institute for the Behavioral and Social Sciences. 
Johnson, W.B., Maddox, M.E., Rouse, W.B., \& Kiel, G.C. (1985). Diagnostic training for nuclear power plant personnel, volume 1: Courseware development (EPRI NP-3829). Palo Alto, CA: Electric Power Research Institute.

Johnson, W.B., Neste, L.O., and Duncan, P.C. (1989). An authoring environment for intelligent tutoring systems. Proceedings of the 1989 IEEE International Conference on Systems, Man, and Cybernetics. Boston, MA, 761-765.

Johnson, W.B., Norton, J.E., and Duncan, P.E., and Hunt, R.M. (1988). Development and demonstration of an intelligent tutoring system for technical training (MITT) (AFHRL-TP-88-8). Brooks AFB, TX: The Air Force Human Resources Laboratory.

Johnson, W.B., and Rouse, W.B. (1981). Analysis and classification of human errors in troubleshooting live aircraft power plants. IEEE Transactions on Systems, Man, and Cybernetics, SMC-12,(3),389-393.

Johnson, W.B., Wiederholt, B.J., and Maddox, M.E. (1986). Diagnostic training demonstration: Instructor and student manuals and sample diskettes (EPRI NP-4493P). Palo Alto, CA: Electric Power Research Institute.

Maddox, M.E., Johnson, W.B., \& Frey, P.R. (1986). Diagnostic training for nuclear power plant personnel, volume 2: Implementation and evaluation (EPRI NP-3829-II). Palo Alto, CA: Electric Power Research Institute.

Massey, L.D., Psotka, J., Mutter, S.A. (Eds.) (1988), Intelligent Tutoring Systems:Lessons Learned. Hillsdale, NJ: Lawrence Erlbaum Associates, Inc.

Neste, L.O. (1989). Overcoming microcomputer constraints in the development of an intelligent tutoring system. Fall Symposium on Computing Research and Development. Houston, TX: University of Houston Clear Lake, Research Institute for the Computing and Information Sciences. 
Norton, J.E., Wiederholt, B.J., and Johnson, W.B. (1991). Microcomputer Intelligence for Technical Training (MITT): The Evolution of an Intelligent Tutoring System (1991). Atlanta, GA: Galaxy Scientific Corporation.

Polson, M.C., and Richardson, J.J. (Eds.) (1988). Foundations of Intelligent Tutoring Systems. Hillsdale, NJ: Lawrence Erlbaum Associates, Inc.

Rouse, W.B. (1979). Problem solving performance of first semester maintenance trainees in two fault diagnostic tasks. Human Factors, 2I(5), 611-618.

Rouse, W.B., and Hunt, R.M. (1984). Human problem solving in fault diagnosis tasks. In W.B. Rouse (Ed.), Advances in Man-Machine Systems Research: Vol 1. Greenwich, CT: JAI Press, 195-222.

Wiederholt, B.J. (1991). MITT Writer User's Manual. Atlanta, GA: Galaxy Scientific Corporation. 


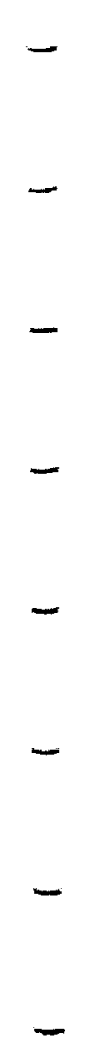

$-$ 